\title{
LA VIVIENDA SECUNDARIA COMO FORMA DE ALOJAMIENTO TURÍSTICO EN LA COMUNIDAD DE MADRID (1970-2010): UNA APROXIMACIÓN ${ }^{1}$
}

\author{
Dolores BRANDIS \\ Universidad Complutense de Madrid.
}

Recibido: 24/10/2011

Devuelto: 29/05/2012

Aceptado: 11/06/2012

RESUMEN: La vivienda secundaria es uno de los tipos de alojamiento utilizado en España por el turismo externo e interno, y tanto litoral como de interior. A pesar de la escasa información estadística que relaciona específicamente este alojamiento con el turismo, su papel manifiesto como forma de residencia por el turista, justifica la investigación aunque, vistas las posibilidades que permiten las fuentes disponibles, tan sólo sea posible un acercamiento al fenómeno. Tras presentar las fuentes de información, repasar los estudios que lo abordan y los significados de los términos incorporados, los enfoques adoptados y los ámbitos territoriales analizados, se intenta una aproximación a la vivienda secundaria como forma de alojamiento turístico en la Comunidad de Madrid. Se analiza la evolución de este parque inmobiliario, su uso turístico y su dinámica en las distintas unidades territoriales (NUTS), atendiendo especialmente al protagonismo que presenta en el parque residencial de los municipios, al considerarlo un indicador suficientemente revelador de su alcance turístico.

PALABRAS CLAVE: segunda residencia, vivienda secundaria, turismo residencial, alojamiento turístico, Comunidad de Madrid.

\section{APPROACH TO TOURISM ACCOMMODATION THROUGH SECONDARY HOUSING IN MADRID REGION (1970-2010)}

ABSTRACT: Secondary housing has become a main source of accommodation by foreign and domestic tourism in Spain, both on the coast and inland areas. Despite little statistical tourism data, this paper makes an approach to secondary housing as a major tourism accommodation in Madrid Region by showing the up-to-date information sources and analysing the available studies from a wide array of working fields and different scopes. The trend of the overall (and tourism) secondary housing has been analysed with special focus on its role at NUTS (Nomenclature of Territorial Units for Statistics) level as a major indicator of municipal tourism capacity.

\footnotetext{
${ }^{1}$ Este trabajo se integra en el Grupo de Investigación "Turismo, Patrimonio y Desarrollo" (referencia 930117) del Departamento de Geografía Humana de la Universidad Complutense de Madrid, dirigido por M. A. Troitiño Vinuesa.
} 
KEY WORDS: secondary housing, second home, residential tourism, tourism accommodation, Madrid Region.

La vivienda secundaria, esto es, la que no se considera principal, es uno de los tipos de alojamiento utilizado en España por el turismo externo e interno, y tanto litoral como de interior, de ahí que sean numerosas las investigaciones que lo abordan. No obstante, la información estadística que permite relacionar la vivienda secundaria con el turismo es escasa y poco precisa, haciendo tan sólo posible una aproximación al fenómeno. En este sentido, un primer acercamiento del papel manifiesto de la vivienda secundaria como forma de residencia por el turista se obtiene a partir de los resultados de las encuestas del Instituto de Estudios Turísticos (Frontur y Familitur) y del Ministerio de Fomento (Movilia) que focalizan la información a partir de la demanda. Frontur contabiliza los turistas extranjeros que se alojan en viviendas secundarias y Familitur y Movilia lo hacen a través de los viajes de los residentes españoles a este tipo de viviendas. También el conteo del Instituto Nacional de Estadística (Censo de Población y Vivienda de 2001) informa de los hogares españoles usuarios de segundas residencias en tiempos de ocio.

Si el análisis de parámetros que relacionan directamente vivienda secundaria y turismo posibilita abordar el fenómeno a nivel nacional y permite comparativas entre autonomías, no es así en el intento de descender al detalle de unidades territoriales menores. Es obligado, pues, limitarse al análisis de la vivienda secundaria como forma de residencia no principal a la hora de pretender conocer su distribución municipal. A partir de aquí, las estadísticas disponibles procedentes del Instituto Nacional de Estadística, del Ministerio de Fomento y de las propias comunidades son prolijas en información.

En consecuencia, este estudio se inicia presentando las fuentes de información centradas no sólo en el uso turístico de la vivienda secundaria, sino también en su condición de vivienda ocupada no principal. A continuación repasa las investigaciones que insisten en su relación con el turismo, destacando los significados de los términos incorporados, los enfoques adoptados y los ámbitos territoriales analizados. Finalmente, intenta una aproximación a la vivienda secundaria como forma de alojamiento turístico en la Comunidad de Madrid. En primer lugar, analiza la evolución de este parque inmobiliario (1970-2010) y de su uso turístico en el conjunto de la Comunidad (1999-2010). Después aborda su dinámica (1970-2001) en las distintas unidades territoriales (NUTS 4$)^{2}$, descendiendo a nivel municipal cuando los

\footnotetext{
${ }^{2}$ Las NUTS (Nomenclatura de Unidades Territoriales a efectos Estadísticos) fue estableci-
} 
resultados derivan en relevantes, y atiende especialmente al protagonismo de la vivienda secundaria en el parque residencial, por ser revelador de la significación turística de los municipios. En último lugar, añade algunas observaciones sobre la dinámica de la construcción de viviendas en la Comunidad y sus distintos territorios a lo largo de la primera década del siglo XXI, a la espera del próximo censo que permita precisar el papel de la vivienda secundaria en el parque residencial.

\section{LAS FUENTES DE INFORMACIÓN}

Viene a ser acostumbrado iniciar las investigaciones presentando el significado de los conceptos sobre los que se va a trabajar, para después pasar al análisis de las fuentes utilizadas. En el caso que nos ocupa, vemos que son muchos los términos sometidos a reflexión y debate, y frecuentes las opiniones enfrentadas y, pese a ello, los estudios se alimentan de las fuentes estadísticas disponibles que imponen, no sólo la definición del concepto, sino también la naturaleza de la información obtenida; de ahí que las investigaciones vean, en ocasiones, limitado el análisis deseado y, en consecuencia, los resultados finales. Aquí se va a proceder en sentido inverso. Primero se contemplan las posibilidades que ofrecen las fuentes de información existentes y, en función de ellas, se ve hasta qué punto permiten aproximarse a un fenómeno complejo y de difícil medición como es el de la segunda residencia como forma de alojamiento turístico.

La participación de las viviendas secundarias como alojamiento turístico en España se pone de manifiesto en las encuestas "Movimientos turísticos en fronteras" (Frontur) y "Movimientos turísticos de los españoles" (Familitur) que realiza el Instituto de Estudios Turísticos, integrado en la Secretaría General de Turismo, de la Secretaría de Estado de Comercio y Turismo del Ministerio de Economía, como órgano responsable de la elaboración, recopilación y valoración de la información relativa al turismo. Las estadísticas se publican con bastante inmediatez; los informes anuales lo hacen de un año para otro, y las notas de coyuntura mensual se pueden consultar con mayor prontitud. Además, las series anuales de Frontur disponibles en línea se remontan a 2001 y las de Familitur a 1999, permitiendo el seguimiento de los datos en los últimos diez años.

da por Eurostat con el fin de ofrecer una división uniforme de unidades territoriales para la elaboración de las estadísticas regionales de la Unión Europea, entrando en plenamente en función en el Parlamento Europeo en 2003. El nivel aquí utilizado es el superior al municipal y se corresponde con las NUTS 4. 
Las encuestas elaboradas por el Instituto de Estudios Turísticos se realizan desde la óptica de la demanda, esto es, la de extranjeros que cruzan las fronteras españolas, en Frontur, y en Familitur la de españoles a través de los viajes que realizan fuera de su entorno habitual, interesándonos aquí los cruces que establecen con el alojamiento utilizado durante el viaje. Las definiciones de los tipos de alojamiento que emplean ambas encuestas son las adoptadas por la Organización Mundial del Turismo en la Conferencia de Ottawa de 1991, y posteriormente refrendadas por la Comisión de Estadística de las Naciones Unidas de 1993, teniendo en cuenta, además, la Metodología Comunitaria sobre Estadísticas de Turismo elaborada por Eurostat en 1998, que aplica las definiciones de la Directiva 95/57/CE del Consejo de la Unión Europea en materia de estadística de turismo.

Cuadro 1. Turistas internacionales según tipos de alojamiento utilizado en el destino principal (2010)

\begin{tabular}{lrr|rr}
\hline \multicolumn{2}{c|}{ España } & \multicolumn{2}{c}{ Comunidad de Madrid } \\
\hline \multicolumn{1}{c}{ Alojamientos } & $\begin{array}{c}\text { Turistas } \\
\text { (miles) }\end{array}$ & $\%$ & $\begin{array}{r}\text { Turistas } \\
\text { (miles) }\end{array}$ & $\%$ \\
\hline Viviendas & 16.129 & 30,6 & 973 & 21,0 \\
\hline propia & 3.964 & 24,6 & 55 & 5,7 \\
familiares y amigos & 7.514 & 46,6 & 790 & 81,2 \\
alquilada & 4.651 & 28,8 & 128 & 13,1 \\
\hline Hoteles y similares & 33.045 & 62,7 & 3.470 & 74,9 \\
\hline Otros & 3.229 & 6,1 & 147 & 3,2 \\
\hline Sin especificar & 275 & 0,5 & 44 & 0,9 \\
\hline Total & 52.678 & 100,0 & 4.634 & 100,0 \\
\hline
\end{tabular}

FUENTE: Elaborado a partir de Instituto de Estudios Turísticos: Familitur (Informe anual de 2010)

La encuesta de Familitur no mejora las cosas al ser la clasificación de alojamientos la misma que en Frontur, sirviendo ahora las objeciones que se apuntaron entonces. La estadística da cuenta del número de viajes cuando hay pernoctación y del tipo de alojamiento donde se hayan pasado la mayor parte de las noches, por lo que cada viaje lleva asociado únicamente un tipo de alojamiento. A partir de esta información, la aproximación al fenómeno de la segunda residencia se hace difícil, pero veamos a que permite llegar. En 2010 de los viajes realizados por residentes en España (148,5 millones) el 73\% lo hicieron a una vivienda y, de éstos, menos de la mitad se dirigieron a una vivienda de su propiedad, lo que representa casi el $30 \%$ del total de viajes. De los viajes que tuvieron como destino la comunidad madrileña $(9,9$ millones) lo hicieron a una vivienda el $64 \%$, dirigiéndose una cuarta parte a la vivienda propia, esto es, el $16 \%$ del total de viajes a cualquier tipo de alo- 
jamiento (CUADRO 2). La encuesta también contempla los hogares residentes en España que tienen acceso a "segunda residencia", entendiendo como tal cualquier vivienda que el hogar disponga distinta a la principal, en propiedad o alquilada, y que esté ubicada fuera del municipio de residencia. En 2010 estos hogares (3.576.650) representan el 21\% del total, de los que el 98\% tienen la vivienda en propiedad, no permitiendo la fuente conocer su ubicación, salvo que sea la propia comunidad de residencia.

Frontur diferencia la vivienda de los restantes tipos de alojamientos turísticos y distingue tres modalidades: vivienda propia, alquilada y de familiares o amigos. De ello resulta que, salvo en el caso identificado como vivienda propia, aparecen incluidas como alojamientos turísticos, no sólo las viviendas secundarias alquiladas o cedidas, sino también las viviendas principales que se alquilan, ceden, comparten o intercambian entre turistas. Así pues, sólo entrarían en la categoría estricta de segunda residencia las que tienen en propiedad los turistas extranjeros. Por otro lado, conviene precisar que Frontur se centra en el alojamiento donde se pernocta el mayor número de noches, escapando de la contabilidad otras viviendas que también se hayan podido utilizar durante el viaje. Pese a todo, el análisis de la fuente permite un acercamiento al fenómeno y así, de los turistas que en 2010 llegaron a España $(52,6$ millones) el $31 \%$ se alojaron en viviendas, de los que una cuarta parte lo hicieron en las de su propiedad, representando el 7,5\% del total de los turistas. Para el caso de los que eligieron la Comunidad de Madrid como destino (4,6 millones) el 21\% se instaló en viviendas, haciéndolo el $6 \%$ en viviendas de su propiedad, bajando al $1 \%$ si se consideran a los que se decidieron por esta comunidad (CUADRO 1).

Cuadro 2. Viajes de residentes según tipos de alojamientos utilizados en destino (2010)

\begin{tabular}{|c|c|c|c|c|}
\hline & \multicolumn{2}{|c|}{ España } & \multicolumn{2}{|c|}{ Comunidad de Madrid } \\
\hline Alojamientos & Viajes & $\%$ & Viajes & $\%$ \\
\hline Viviendas & 108.866 .839 & 73,2 & 6.373 .077 & 63,9 \\
\hline propia & 43.044 .806 & 39,5 & 1.579 .853 & 24,8 \\
\hline familiares y amigos & 53.790 .169 & 49,4 & 4.003 .544 & 62,8 \\
\hline alquilada & 12.031 .864 & 11,1 & 789.680 & 12,4 \\
\hline Hoteles y similares & 26.408 .299 & 17,8 & 2.713 .756 & 27,2 \\
\hline Otros & 13.316 .055 & 9,0 & 892.493 & 8,9 \\
\hline Total & 148.591 .193 & 100,0 & 9.979 .326 & 100,0 \\
\hline
\end{tabular}

FuENTE: Elaborado a partir de Instituto de Estudios Turísticos: Familitur (Informe anual de 2010) 
El Ministerio de Fomento realiza desde el año 2000 la encuesta sobre movilidad de las personas residentes en España (Movilia) para ayudarse en la planificación de las infraestructuras. Se centra en el motivo del viaje y singulariza el "ir a segunda residencia", independientemente de otros posibles motivos. Define como segunda residencia aquellas que el informante utiliza o puede utilizar con cierta frecuencia y disponibilidad, aunque no sea el propietario. Si a primera vista sorprende el abultado número de viajes de la encuesta se debe a su consideración del viaje, que equipara con cada uno de los desplazamientos efectuado por una persona desde el momento de salir de su lugar de residencia hasta que regresa a él, contabilizando, por ello, tanto los viajes de ida como de vuelta, así como todos los desplazamientos realizados por cualquier finalidad. Aun teniendo en cuenta las peculiaridades de la estadística, los datos revelan que la segunda residencia motiva cerca de la cuarta parte de los viajes que se realizan por el territorio nacional, teniendo el $11 \%$ como destino la Comunidad de Madrid, incluidos los que se realizan dentro de la propia comunidad (CUADRO 3).

Cuadro 3. Viajes de los residentes a segundas residencias según destino 2007

\begin{tabular}{ccc|ccc}
\hline \multicolumn{3}{c|}{ España } & \multicolumn{3}{c}{ Comunidad de Madrid } \\
\hline$N^{o}$ viajes & A $2^{a}$ res. & $\%$ & $N^{o}$ viajes & A $2^{a}$ res. & $\%$ \\
\hline 519.026 .900 & 92.989 .000 & 21,74 & 43.044 .000 & 4.799 .600 & 11,15 \\
\hline
\end{tabular}

FUENTE: Elaborado a partir del Ministerio de Fomento. MoviLIA (2007)

El Censo de Población y Viviendas es la fuente más idónea para trabajar el fenómeno de la segunda residencia, que no su funcionalidad turística, y es la empleada fundamentalmente en las investigaciones. Utiliza de forma exclusiva el término "vivienda secundaria" manteniendo desde 1970 la misma definición: "una vivienda familiar es considerada secundaria cuando es utilizada solamente parte del año, de forma estacional, periódica o esporádicamente y no constituye la residencia principal habitual de una o varias personas. Puede ser, por tanto, una casa de campo, playa o ciudad que se emplee en vacaciones, verano, fines de semana, trabajos temporales o en otras ocasiones". Así pues, se identifica distinguiéndose de la vivienda familiar principal, de las desocupadas y de otros tipos de vivienda, pero no insiste en su uso turístico. Sin embargo, el Censo de 2001, el último realizado, aborda por primera vez los hábitos turísticos de las familias e informa de los hogares que usan otra vivienda distinta a la principal como segunda residencia (en propiedad, alquilada o cedida gratis) en vacaciones o fines de semana para pasar las vacaciones, y de emplear más de una sólo hace referencia a la más utilizada. Atendiendo a los datos resulta que 2,1 millones hogares españoles 
disponen de segunda residencia con fines turísticos ${ }^{3}$, teniéndola ubicada en la comunidad madrileña el 5,5\%. El exceso que se observa de viviendas secundarias localizadas en la Comunidad sobre los hogares españoles que las disfrutan podrá explicarse, entre otras cosas, al no contabilizarse las más de una segunda vivienda que pueden tener las familias, las de extranjeros no residentes en España, ni las usadas con fines no turísticos (CUADRO 4).

Cuadro 4. Viviendas secundarias y hogares que disponen de una segunda vivienda con fines turísticos según destino en 2001.

\begin{tabular}{lrrr}
\hline & España & CAM & $\%$ \\
\hline $\mathrm{N}^{\circ}$ de viviendas secundarias & 3.351 .300 & 274.713 & 8,19 \\
$\begin{array}{l}\text { Hogares que disponen de segunda } \\
\text { vivienda con fines turísticos }\end{array}$ & 2.134 .084 & 116.817 & 5,47 \\
\hline
\end{tabular}

FuENTE: Elaborado a partir del INE. Censos de Población y Vivienda de 2001

Otras fuentes publicadas pueden servir de complemento al fenómeno de la segunda residencia e, indirectamente, a su aproximación como alojamiento turístico. Es el caso del Nomenclator (INE) que, además, permite el análisis a nivel municipal. Las Estadísticas de Construcción, Edificación y Vivienda (Ministerio de Fomento), el Catastro Inmobiliario (Ministerio de Economía y Hacienda), la información del Instituto Español de Comercio Exterior (Ministerio de Industria, Turismo y Comercio) o la Encuesta Sociodemográfica (Instituto Nacional de Estadística) aportan información a nivel nacional y autonómico que, en ocasiones, procesan las Consejerías de Urbanismo de las comunidades autónomas y la ofrecen desagregada por unidades territoriales menores. También, tal y como ponen de manifiesto algunas investigaciones, son de utilidad los estudios o informes de las propias Consejerías o de asociaciones, empresas y grupos especializados, caso de la Asociación de Empresas Constructoras de ámbito nacional (DELGADO, 2008), Asociación de Promotores y Constructores de España (Ros, 2003), Asociación de Promotores Inmobiliarios de Madrid y la Asociación de Empresas Turísticas Españolas (VALENZUELA, 2007), Euroconstruct (VERA, 2005) o el Grupo i (REQUEJO, 2007). Finalmente, cabe contar con el acercamiento directo al objeto de estudio a través de las encuestas y entrevistas realizadas por los propios investigadores a los agentes implicados (LÓPEZ et AL., 2004; HUETE, 2008, 2010; HUETE et AL., 2008).

\footnotetext{
${ }^{3}$ Este número de hogares contrasta por defecto con la estimación de Familitur para el mismo año, que es de 13,1 millones, al entender como hogar viajero "cuando cualquiera de sus miembros ha efectuado al menos un viaje con pernoctación", mientras que el censo considera al hogar como unidad.
} 


\section{LA SEGUNDA RESIDENCIA Y EL TURISMO RESIDENCIAL: SIGNIFICADOS, ENFOQUES Y ÁMBITOS DE ESTUDIO}

Son muchos los términos utilizados en las investigaciones a la hora de poner en relación las viviendas secundarias con el turismo. Entre todos, los más usuales son los de "segunda residencia" y "turismo residencial", aunque ambos son sometidos a crítica, tachándose uno de ambiguo y el otro de contradictorio. Los términos asociados a ellos son numerosos y se emplean en función de casuísticas variadas como son, entre otras, el tiempo de uso, la distancia de la residencia principal, el régimen de tenencia asociado, la forma que revisten en el mercado turístico o el modo de incidir en el territorio. Así, pues, se reconocen los de segunda vivienda, vivienda turística, familiar de uso turístico, vacacional, turístico-residencial, hábitat vacacional, urbanización vacacional, residencia múltiple, alojamiento turístico privado, no reglado o extrahotelero, promociones de alojamientos turísticos privados, de uso compartido, o al margen de la estructura urbana tradicional, turismo de segunda residencia, de estancia, de vacaciones, de proximidad, familiar, sedentario, o turismo inmobiliario. No obstante, algunos vocablos tienen un claro significado, caso de "residencia múltiple", más relacionado con las nuevas formas de vida de los ciudadanos que con su uso turístico, o "turismo inmobiliario", dado su enfoque desde el punto de vista de la promoción,

Desde luego que resulta tentador adentrarse en el debate terminológico, pero este no es el momento cuando, además, hay estudios que lo abordan con mayor o menor profundidad (VALENZUELA, 1976, 2007; PALLARÉS, 1991; TORRES, 2003; LÓPEZ, 2003; LÓPEZ el AL, 2004; RODRÍGUEZ, 2004; GARCíA, 2005; MAZÓN et AL., 2005; MiLláN, 2005; DELGADO, 2008; HUETE, 2008). Cabría citar aquí también los realizados desde los propios organismos oficiales (IET e INE) que insisten en las definiciones empleadas (RODRÍGUEZ et AL., 2003; VARELA, et AL., 2003). Es cierto que la discusión es siempre fructífera, pues con ello se perfila y enriquece el sentido de los términos, pero también lo es que a la hora de abordar los estudios empíricos no queda más remedio que acatar los significados fijados por las fuentes oficiales, únicas que aportan datos con referencia territorial. El problema surge cuando los términos empleados, a veces justificados por adecuarse mejor con el fenómeno estudiado, se apoyan en los datos de las estadísticas oficiales, cuyas definiciones tienen a veces significados poco homologables con aquellos. Pareciera, pues, conveniente partir del sentido de los términos empleados en las fuentes oficiales y, a partir de ahí, hacer las matizaciones y acepciones pertinentes que los enriquezcan y permitan ajustarlos mejor con las plurales realidades derivadas de un fenómeno tan complejo como el de la vivienda secundaria utilizada como alojamiento turístico. 
Tras revisar más de cincuenta estudios sobre la segunda residencia como forma de alojamiento turístico, se observa la pluralidad de disciplinas que lo tratan en base a las dimensiones económicas, urbanísticas, medioambientales, sociodemográficas, etc. que presenta el fenómeno (HUETE, 2010). Los niveles territoriales analizados van desde el nacional y autonómico hasta el municipal, sin olvidar diversos ámbitos espaciales como los metropolitanos, costeros o de interior. Para dar razón de ellos, y por comodidad expositiva, se opta por agruparlos por ámbitos territoriales de estudio. Los realizados a nivel nacional que incorporan comparaciones entre comunidades autónomas o provincias no son muchos, pues la fuente más utilizada, el recuento censal del INE, sólo permite su análisis cada diez años (ORTEGA, 1975; CANTO, 1983b; LÓPEZ, 2003; SERRANO, 2003).

Casi todas las comunidades autónomas cuentan con estudios, siendo las más trabajadas Cantabria (DELGADO et AL, 2005; DELGADO, 2007, 2008), Asturias (VAlDÉS et AL. 2004; CORTIZO, 2007), Navarra (SolA, 1986), Cataluña (PALLARÉS, 1991; FRAGUELL, 1994; GONZÁLEZ, 2005), Islas Baleares (SALVÁ, 1979, 1991; SALVÁ et AL. 1985, 1993; MATEU, 2003), CastillaLeón (CANTO, 1981; CóRDOBA et AL, 2000), Madrid (VALENZUELA, 1976, 1977, 2003; CHUVIECO et AL. 1983; CANTO, 1983a, 1987, 1994), Castilla-La Mancha (GARCíA et AL., 2008), Valencia (MIRANDA, 1981; NAVALÓN, 1995; MARTíNEZ, et AL., 2003; MAZÓN et al, 2005a, 2005b: HUETE, 2010), Murcia (MILlÁN, 2005; SERRANO, 2007), Andalucía (RAYA, 2003; RodríGUeZ, 2004; NAVARRO, 2007), Canarias (PARREÑo, 2007). Se añaden, además, los que abordan en conjunto la costa mediterránea (VERA, 2005; HUETE, 2008).

\section{LA VIVIENDA SECUNDARIA COMO FORMA DE ALOJA- MIENTO TURÍSTICO EN LA COMUNIDAD DE MADRID (1970-2010)}

No son precisamente pocas las investigaciones realizadas sobre la Comunidad de Madrid, siete en total, aunque sí lo son los autores, sólo cuatro, tal y como se muestra en el epígrafe anterior. Sus autores son geógrafos y el conjunto de los estudios cubren sobradamente las perspectivas que se debieran esperar desde esta disciplina. Lo avanzado en el tiempo de la primera investigación (VALENZUELA, 1977) y la fecha de la última (VALENZUELA, 2003) permite hacer el seguimiento del proceso seguido por la vivienda secundaria hasta 2001, fecha del último censo de población y vivienda. Pese a ello, puede tener interés dar aquí la visión de conjunto entre 1970 y 2001, parcelada en los trabajos anteriores, unificando el tratamiento de análisis, y actualizar el fenómeno hasta 2010. Además, se añaden algunos parámetros poco contemplados anteriormente, y se presentan los resultados basadas en las NUTS 
4 de la Comunidad, zonificación estadística oficial del Instituto de Estadística de Madrid desde 2003 para ámbitos territoriales superiores al municipal.

\section{III.1. La dinámica del parque inmobiliario de la vivienda secundaria a la luz de las coyunturas económicas (1970-2010)}

Durante la década de 1960, y en respuesta a una etapa de crecimiento económico, la población madrileña experimenta un fuerte crecimiento (50\%) al pasar de dos millones y medio a superar los tres y medio, siendo el del conjunto del parque residencial mayor (70\%), de 671.000 viviendas a más de un millón. Es entonces cuando empiezan a tomar cuerpo las viviendas secundarias, pues de las 13.489 unidades contabilizadas en 1960 llegan a casi 50 mil en 1970, lo que supone un incremento del 264\%. Y así, el primer estudio sistemático realizado sobre la segunda residencia madrileña reconoce, excluido el municipio capitalino, unas 300 acciones inmobiliarias anteriores a 1970, entre urbanizaciones de chalés, apartamentos y desarrollos espontáneos, localizadas en las proximidades de los cascos urbanos o en suelo rural (COPLACO, 1980).

Los CUADROS 5 y 6 permiten observar la dinámica de los distintos tipos de viviendas hasta 2001 y su relación con la población de derecho en las NUTS madrileñas ${ }^{4}$. Se advierte que en la década de los setenta se retrae el crecimiento demográfico (25\%) y del parque residencial (50\%) al prolongarse sólo hasta mediados de la década la etapa de bonanza económica. En 1973 se alcanza el máximo histórico de construcción de viviendas, unas 70.000, para descender sistemáticamente a partir de esta fecha hasta un mínimo de 31.000 en 1980 (GAGO, 1983), en correspondencia con la crisis del petróleo que se mantendrá hasta bien entrada la década de 1980. Por el contrario, las viviendas secundarias experimentan un fuerte crecimiento (166\%) al ampliarse la demanda más allá de los estratos medios de población, usuarios acostumbrados hasta el momento. $\mathrm{Y}$ así, el catálogo de urbanizaciones ilegales (COMUNIDAD DE MADRID, 1984) recoge, entre las 107 registradas, más de treinta promociones iniciadas en los primeros años de la década, al incorporarse una demanda de menor nivel de renta que adquiere chalés de muy escasa calidad o parcelas en donde autoconstruirá una segunda residencia.

Pero la crisis también hará mella en este mercado, como pone en evidencia el citado estudio de Coplaco al dar cuenta de más de 500 acciones inmobiliarias aparecidas a lo largo de la década de 1970, donde todavía hay más de

\footnotetext{
${ }^{4}$ Los datos referidos a la Comunidad se corresponden con los obtenidos de los totales municipales para hacerlos coincidir con los de los cuadros y mapas diseñados a niveles territoriales menores (NUTS y municipios).
} 
tres mil chalés en venta y con una cuarta parte de los usuarios de parcelas sin edificar con intención de venderlas. Por otra parte, las viviendas vacías también muestran un incremento importante en respuesta a la crisis, al producirse una alteración de las pautas demográficas migratorias que rebajan el crecimiento de la población, traduciéndose en 1981 en 52 viviendas desocupadas por cada mil habitantes, cuando diez años antes era tan sólo de 39.

Cuadro 5. Evolución del parque de viviendas y relación con la población de derecho en la Comunidad de Madrid (1970-2001)

\begin{tabular}{|c|c|c|c|c|c|c|c|c|}
\hline \multirow{2}{*}{ Viviendas } & \multicolumn{2}{|c|}{1970} & \multicolumn{2}{|l|}{1981} & \multicolumn{2}{|l|}{1991} & \multicolumn{2}{|l|}{2001} \\
\hline & $N^{o}$ & $\%$ & $N^{o}$ & $\%$ & $N^{o}$ & $\%$ & $N^{o}$ & $\%$ \\
\hline Principales & 947.263 & 252 & 1.336 .749 & 285 & 1.512 .294 & 306 & 1.873 .671 & 349 \\
\hline Secundarias & 49.106 & 13 & 130.515 & 28 & 159.305 & 32 & 275.704 & 51 \\
\hline Vacías & 146.070 & 39 & 244.576 & 52 & 251.540 & 51 & 328.648 & 61 \\
\hline Totales & 1.142 .439 & 304 & 1.711 .840 & 365 & 1.923 .139 & 389 & 2.478 .024 & 461 \\
\hline Población & 3.761 .348 & & 4.686 .895 & & 4.947 .555 & & 5.372 .433 & \\
\hline
\end{tabular}

$\%$ o : viviendas por mil habitantes.

FuENTE: Elaborado a partir del INE. Censos de Población y Vivienda.

Cuadro 6. Crecimiento del parque de viviendas y de la población de derecho de la Comunidad de Madrid por periodos intercensales (1970-2001)

\begin{tabular}{lrrrrrr}
\hline \multicolumn{1}{c}{ Viviendas } & Saldo & Incr. $(\%)$ & Saldo & Incr. $(\%)$ & \multicolumn{1}{c}{ Saldo } & Inc. $(\%)$ \\
\hline Principales & 389.486 & 41 & 175.545 & 13 & 361.377 & 24 \\
Secundarias & 81.409 & 166 & 28.790 & 22 & 116.399 & 73 \\
Vacías & 98.506 & 124 & 6.964 & 3 & 77.108 & 30 \\
\hline Total & 569.401 & 50 & 211.299 & 12 & 554.885 & 29 \\
\hline Población & 925.547 & 24,6 & 260.660 & 5,5 & 424.878 & 8,5 \\
\hline
\end{tabular}

Fuente: Elaborado a partir del INE. Censos de Población y Vivienda.

Al remitir el crecimiento demográfico y migratorio interno se recortan las previsiones demográficas y las futuras necesidades de vivienda y, en consecuencia, se retrae el mercado inmobiliario durante el primer quinquenio de la década de los ochenta. La situación de debilidad del mercado se interrumpe a raíz de las medidas para relanzar el crecimiento económico, lo que da lugar a la primera burbuja inmobiliaria (1986-1992) que afecta básicamente a los precios pero no tanto al volumen construido, y que muere por estrangulamiento financiero tras los festejos de 1992 (NAREDO, 1996). En 1985 la liberalización del crédito y el decreto Boyer, al desgravar por invertir en vivienda harán de la industria de la construcción un importante motor del despliegue económico. Con ello se pretende impulsar la compra de segundas residencias para que el ahorro familiar de las clases medias alimente el sector inmobiliario y arrastre el amplio universo productivo que gira en torno a la 
vivienda y su equipamiento (Roch, 2002). Y así, en una década con el índice de crecimiento demográfico congelado (5\%), el parque residencial en su conjunto crece poco (12\%), poco también las viviendas principales (13\%) y menos aún las vacías (3\%), al contrario de las secundarias (22\%) en respuesta a las importantes bonificaciones fiscales.

En la década de 1990, tras el breve periodo de declive económico y atonía del mercado inmobiliario de los primeros años, se abre una etapa de recuperación económica que dará paso en 1997 al boom inmobiliario que dura hasta 2005 , momento en que se empiezan a manifestar los primeros síntomas de la crisis económica que azota al país desde entonces. Aunque la burbuja inmobiliaria como la crisis que le sigue no son fenómenos exclusivos de España, pues se reconocen con diferencias en los tiempos y magnitud en todo el mundo desarrollado, está demostrado que la burbuja inmobiliaria española no se puede comparar con otros países en cuanto a viviendas construidas y al nivel alcanzado en el crecimiento de los precios y del crédito inmobiliario.

Si se confronta el ligero incremento demográfico de la década de los noventa $(8,5 \%)$ con el del parque de viviendas (29\%) se aprecian los efectos del boom inmobiliario. Y de nuevo es el crecimiento de la vivienda secundaria $(73 \%)$ el mayor responsable del aumento residencial, elevando la relación de este tipo de viviendas por mil habitantes a 51 cuando diez años antes era de 32. Y también se incrementan las vacías (30\%) llegando esta relación a 61. Aunque la subida de los precios se disparó muy por encima del crecimiento de los salarios, fue la facilidad de conseguir créditos a bajo interés, inéditos en España hasta la entrada del euro, junto con el alargamiento de los plazos, los que fomentaron la demanda y la compra de viviendas. Y hubo compradores de primera y segunda vivienda, y compradores de reposición, pero también quienes lo hicieron como inversión, todos estimulados por las progresivas facilidades financieras de entradas, costes y plazos en los créditos hipotecarios. En este ambiente de coyuntura alcista del mercado inmobiliario, serán las expectativas futuras de los precios el factor principal de los que adquieren viviendas con el ánimo de invertir.

Además, el protagonismo del incremento de población recae en los extranjeros, pues su llegada masiva a partir de 1996 provoca la apertura de un nuevo ciclo urbano de fuerte crecimiento demográfico, tanto en el interior del conjunto metropolitano tradicional como en su, cada vez más amplia, periferia externa (POZO et AL, 2009). Pero en esta época de subidas espectaculares del precio de la vivienda el grueso de la demanda no recae en la población inmigrante, sino en las rentas medias y medias bajas enriquecidas en la coyuntura económica alcista. Éstos son buena parte de los compradores de vi- 
viendas para revender, a la vista del alza imparable de los precios, y que con la crisis pasarán a engrosar los parques de segunda residencia y de vacías.

Al ser el último censo de 2001, los datos para años posteriores proceden de otras fuentes de información que perfilan menos el fenómeno de la segunda residencia. La Secretaría de Estado de Vivienda y Actuaciones Urbanas del Ministerio de Fomento publica en 2001 la estimación del número de viviendas hasta 2010 y para las mismas fechas el Instituto Nacional de Estadística lo hace de la población en el Padrón Continuo (CUADRO 7). En la estimación del Ministerio las viviendas familiares las clasifican en "principales" y "no principales", pues le interesan sobre todo las primeras a efectos de la política de vivienda y engloba, en consecuencia, dentro de las no principales las secundarias y las vacías. Las predicciones realizadas desde una coyuntura demográfica e inmobiliaria alcista estiman para la primera década del siglo XXI unos incrementos que, comparados con los registrados en la década anterior, se muestran superiores para la población (20\%) y para las viviendas principales (29\%), menor para el total de viviendas (19\%) y negativo para las viviendas no principales $(-11 \%)$, rebajando, en consecuencia, el número de estas últimas por mil habitantes a 83, cuando diez años antes era de 112.

Cuadro 7. Estimación de las viviendas familiares y población de derecho de la Comunidad de Madrid (2001-2010)

\begin{tabular}{lrrrrr}
\hline \multirow{2}{*}{ Viviendas } & \multicolumn{2}{c}{2010} & \multicolumn{3}{c}{$2001-2010$} \\
\cline { 2 - 6 } & Número & $\%$ & $\%$ & Saldo & Incr. (\%) \\
\hline Principales & 2.425 .145 & 82 & 376 & 551.474 & 29 \\
No principales & 537.770 & 18 & 83 & -66.582 & -11 \\
\hline Totales & 2.962 .915 & 100 & 459 & 484.892 & 19 \\
\hline Población & 6.456 .684 & & & 1.086 .251 & 20 \\
\hline
\end{tabular}

FuENTES: Secretaría de Estado de Vivienda y Actuaciones Urbanas del Ministerio de Fomento y Padrón Continuo del Instituto Nacional de Estadística (2001).

El pinchazo de la burbuja inmobiliaria se deja sentir desde 2007, pues aunque dos años antes se empiecen a observar los primeros síntomas de desaceleración, la máquina inmobiliaria no puede frenar en seco cuando ya está lanzada, de ahí que la Estadística de Obras en Edificación del Ministerio de Fomento registre para la comunidad madrileña desde 2007 el descenso del total de viviendas terminadas y desde 2004 de los encargos de dirección de obra nueva, y que en 2010 se contabilicen 51.101 viviendas nuevas sin vender. Desde la perspectiva actual, es evidente que el pasado boom inmobiliario hizo de España el país con más viviendas por habitante de la Unión Europea, al incrementar en más de una cuarta parte el stock de viviendas (NAREDO, 2011). 


\section{III.2. El uso turístico de la vivienda secundaria (1999-2010)}

El primer año en que la encuesta Frontur ofrece en línea información detallada de los tipos de alojamientos turísticos por destinos es 2003, cuando el 19\% (607 mil) de los más de tres millones de turistas extranjeros que eligen la comunidad madrileña como destino principal se aloja en segundas residencias. A partir de entonces esta representación no ha dejado de aumentar hasta llegar en 2009 al 26\% (1.109 mil) de los casi cinco millones de turistas instalados en todo tipo de alojamiento. La vivienda secundaria cedida por familiares o amigos es la más utilizada, seguida de la alquilada y de la pro$\mathrm{pia}^{5}$. Es a partir de 2010 cuando la afluencia de turistas a la Comunidad desciende a poco más de los cuatro millones y medio y se rebaja la representación de la residencia secundaria al 21\% (973 mil) (GRÁFICO 1).

Gráfico 1. Turistas extranjeros alojados en segundas residencias en la Comunidad de Madrid (2003-2010)

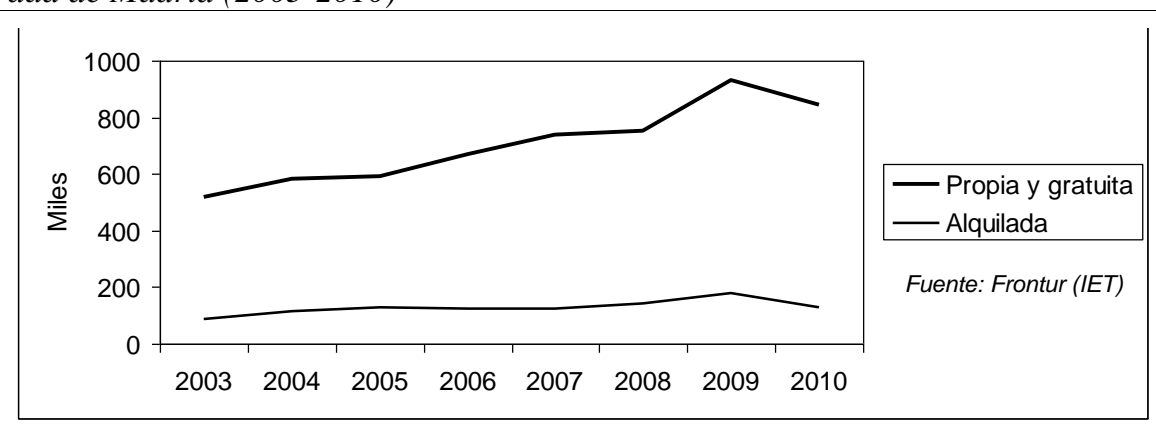

FUENTE: Fontur (IET)

La encuesta Familitur registra entre 1999 y 2010 oscilaciones en los viajes de españoles a segundas residencias madrileñas, con el máximo en 2006 (7.716 mil) y el mínimo en 2002 (6.092 mil). Es la vivienda cedida por familiares o amigos la que acumula siempre el mayor número de viajes (del 42 al $63 \%$ de los viajes), seguida de la propia (del 21 al 55\%) y la alquilada (del 2 al 22\%). En la dinámica temporal se observa que los viajes a la vivienda en propiedad descienden a partir de 2005, al tiempo que aumentan los dirigidos a las alquiladas, quizás al optar los hogares por alquilar la vivienda secundaria a resultas de la incidencia de la crisis o por la desaparición del mercado de las secundarias transformadas en principales (GRÁFICO 2).

\footnotetext{
${ }^{5}$ En el gráfico presentado se agrupan las viviendas propias y las cedidas por familiares o amigos, pues hasta 2006 no aparecen individualizadas.
} 
Con respecto a la posibilidad de conocer los hábitos turísticos de las familias que ofrece el Censo de 2001, ya comentado en el primer epígrafe de este trabajo, sólo recordar que en ese año disfrutaron de una segunda residencia con fines turísticos en la comunidad madrileña un total de 116.817 hogares españoles, y añadir ahora que un $73 \%$ de los mismos (84.862) residían en la propia comunidad.

Gráfico 2. Viajes de los españoles a segundas residencias de la Comunidad de Madrid (1999-2010)

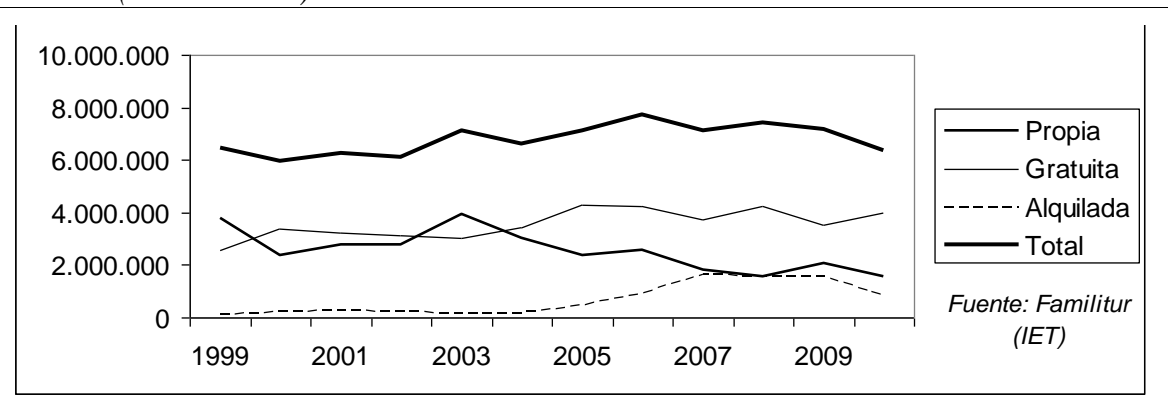

FUENTE: Familitur (IET)

\section{III.3. La dinámica territorial de la vivienda secundaria (1970-2001)}

Se utilizan aquí, especialmente, las unidades territoriales estadísticas (NUTS 4) establecidas por la Comunidad de Madrid en 2003 para la división del territorio a un nivel superior al municipal. Se es consciente de que los resultados de los indicadores, especialmente económicos y demográficos, aplicados para confeccionar las actuales unidades territoriales, dan lugar a agrupaciones de municipios que en décadas pasadas ofrecerían parámetros que estarían lejos de correr parejos, de ahí las diferencias que puede haber entre las NUTS y las comarcas geográficas tradicionales o las delimitaciones del ámbito metropolitano al uso. Tampoco coinciden exactamente con las empleadas por M. Valenzuela y C. del Canto a la hora de presentar la información en unidades territoriales superiores a la municipal. No obstante, con el objeto de establecer comparativas en el tiempo y facilitar su seguimiento a futuro, para fechas anteriores se han adaptado los municipios a la zonificación oficial actual (MAPA 1).

La Comunidad pasa de tener 49 mil viviendas secundarias en 1970 a 276 mil en 2001, aumentando su representación en el parque residencial del 5 al 11\% (CUADROS 8 y 9). El mayor crecimiento se produce en la década de 1970 (166\%), desciende ostentosamente en la siguiente (22\%) y tiende a recuperarse en la década de 1990 (73\%). El mayor responsable de esta dinámi- 
Cuadro 8. Evolución de las viviendas secundarias y porcentaje sobre el total de viviendas en las NUTS de la Comunidad de Madrid (1970-2001)

\begin{tabular}{lrrrrrrrr}
\hline \multirow{2}{*}{ NUTS } & \multicolumn{1}{c}{1970} & & \multicolumn{1}{c}{1981} & & \multicolumn{1}{c}{1991} & & 2001 \\
\cline { 2 - 9 } & $N^{o}$ & $\%$ & $N^{o}$ & $\%$ & $N^{o}$ & $\%$ & $N^{o}$ & $\%$ \\
\hline Municipio Madrid & 19.147 & 2 & 33.952 & 3 & 43.691 & 4 & 106.192 & 8 \\
Norte Metropolitano & 1.956 & 9 & 4.473 & 10 & 6.119 & 10 & 9.219 & 9 \\
Este Metropolitano & 510 & 1 & 1.992 & 2 & 3.459 & 3 & 8.548 & 5 \\
Sur Metropolitano & 1.353 & 1 & 8.008 & 3 & 6.733 & 2 & 14.852 & 4 \\
Oeste Metropolitano & 6.076 & 33 & 18.366 & 34 & 21.687 & 24 & 23.803 & 23 \\
Sierra Norte & 1.920 & 25 & 7.105 & 48 & 10.540 & 55 & 18.151 & 61 \\
Sierra Central & 10.148 & 3 & 30.122 & 66 & 35.570 & 61 & 45.438 & 49 \\
Sierra Sur & 3.115 & 33 & 10.160 & 61 & 10.847 & 55 & 16.953 & 57 \\
Noreste Comun. & 373 & 12 & 2.025 & 29 & 3.475 & 34 & 6.055 & 55 \\
Sureste Comunidad & 2.710 & 16 & 8.542 & 34 & 10.883 & 35 & 14.031 & 30 \\
Suroeste Comun. & 1.798 & 24 & 5.770 & 39 & 6.301 & 33 & 12.462 & 33 \\
\hline Comunidad & 49.106 & 5 & 130.515 & 8 & 159.305 & 8 & 275.704 & 11 \\
\hline
\end{tabular}

FuENTE: Elaborado a partir de INE: Censos de Población y Vivienda.

Cuadro 9. Crecimientos relativos del parque residencial total y de las viviendas secundarias en las NUTS de la Comunidad de Madrid en periodos intercensales (1970-2001)

\begin{tabular}{lrrrrrr}
\hline \multirow{2}{*}{ NUTS } & \multicolumn{2}{c}{$1970-1981$} & \multicolumn{2}{c}{ 1981-1991 } & \multicolumn{2}{c}{ 1991-2001 } \\
\cline { 2 - 6 } & \multicolumn{2}{c}{ Incremento (\%) } & \multicolumn{2}{c}{ Incremento (\%) } & \multicolumn{2}{c}{ Incremento (\%) } \\
\cline { 2 - 6 } & Total viv. & 2da. viv. & Total viv. & 2da. viv. & Total viv. & 2da. viv. \\
\hline Municipio Madrid & 22 & 77 & 6 & 29 & 18 & 143 \\
Norte Metropolitano & 117 & 129 & 47 & 37 & 47 & 51 \\
Este Metropolitano & 203 & 290 & 17 & 74 & 16 & 147 \\
Sur Metropolitano & 223 & 492 & 12 & -16 & 31 & 121 \\
Oeste Metropolitano & 188 & 202 & 67 & 18 & 18 & 10 \\
Sierra Norte & 90 & 270 & 30 & 48 & 16 & 72 \\
Sierra Central & 40 & 197 & 27 & 18 & 59 & 28 \\
Sierra Sur & 78 & 226 & 19 & 7 & 49 & 56 \\
Noreste Comunidad & 124 & 443 & 45 & 72 & 9 & 74 \\
Sureste Comunidad & 46 & 215 & 23 & 27 & 46 & 29 \\
Suroeste Comunidad & 99 & 221 & 30 & 9 & 95 & 98 \\
\hline Comunidad & 50 & 166 & 10 & 22 & 31 & 73 \\
\hline
\end{tabular}

FUENTE: Elaborado a partir de INE: Censos de Población y Vivienda.

ca es el municipio de Madrid al concentrar siempre más de la cuarta parte de las viviendas secundarias de la Comunidad. Es indudable que poseer una segunda residencia en la capital es atractivo para el turismo nacional y extranjero, tanto por los recursos que ofrece la ciudad como por su papel de distribuidor hacia otros destinos patrimoniales de la propia comunidad y de su entorno. Pero el elevado número de viviendas secundarias se explica, también, por lo que es costumbre habitual entre los censados, como es declarar como tales las adquiridas para engrosar el patrimonio familiar o con fines especu- 
lativos en periodos de crecimiento inmobiliario. Práctica, por otra parte, no exclusiva de la capital, pero que adquiere aquí gran magnitud por su dimensión demográfica, como refleja el incremento del $143 \%$ de los años noventa, al socaire del boom inmobiliario, y que en 2001 representen el $8 \%$ del parque residencial cuando diez años antes era el $4 \%$. Por otra parte, este incremento de las segundas residencias en la capital no tiene parangón con el registrado en el primer boom inmobiliario de la década de 1970, al que duplica.

Mapa 1. NUTS de la Comunidad de Madrid

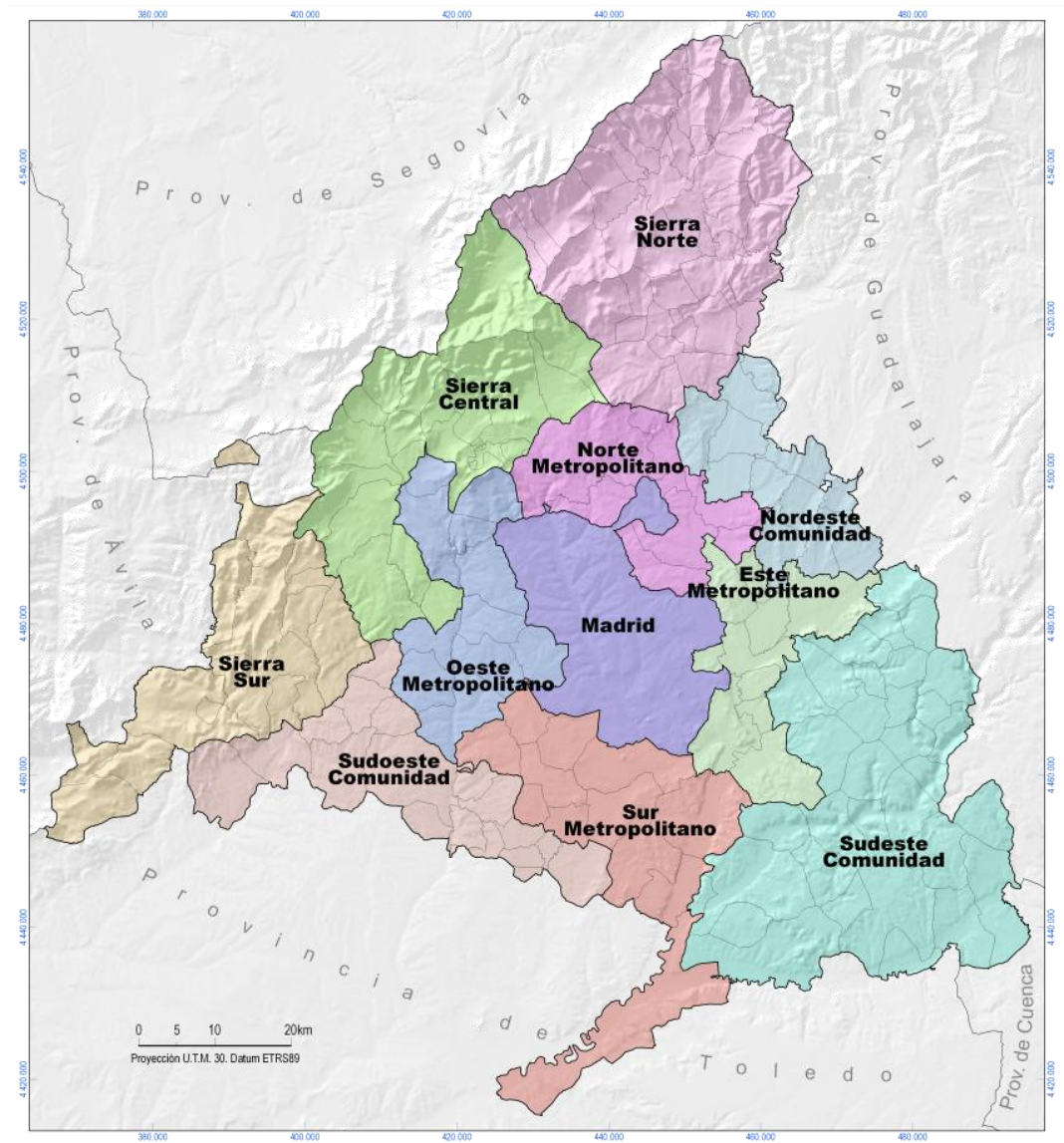

FuENTE: Comunidad de Madrid

En 1970 sólo en los municipios de Rivas-Vaciamadrid, El Vellón y Cobeña están ausentes las viviendas secundarias, y en otros once no superan las cin- 
co unidades, estando localizadas casi la mitad en la Sierra Norte. En el 92\% restante ya hacen acto de presencia, pero las situaciones son contrastadas. Destaca el protagonismo de la Sierra Central, donde las cumbres de Guadarrama le consolidan como feudo de tradición turística, con más de 10 mil viviendas, superando las mil unidades los municipios de San Lorenzo de El Escorial, Cercedilla, El Escorial y Guadarrama. Le sigue el Oeste metropolitano, que prolonga el atractivo natural serrano hasta casi tocar la capital, rebasando el millar de secundarias el de Galapagar. Más allá de estas unidades territoriales la presencia de segundas residencias es mucho menor.

La dinámica progresiva de las viviendas secundarias en los distintos territorios hasta 2001 refleja en general la tónica temporal que sigue el conjunto de la Comunidad, pero difiere en la cuantía del crecimiento dependiendo de la situación de partida. Así, entre 1970-1981 la Sierra Central y el Norte metropolitano presentan los incrementos más bajos, entre 100 y $200 \%$, mientras que otros territorios superan el $400 \%$, siendo los más favorecidos los de menores efectivos en origen (los metropolitanos del Este y Sur y el periférico del Nordeste). De la atonía del crecimiento de la década de 1980, incluso negativa en casi una cuarta parte de los municipios madrileños, sólo despuntan los incrementos del Este metropolitano y periferia del Noreste al prolongar, si bien con menor intensidad, la dinámica de la década anterior.

El crecimiento alcista de la segunda residencia entre 1991 y 2001 coincide con el boom inmobiliario, asociado a una política regional extremadamente permisiva a partir de 1997 en lo referente a la ocupación del suelo. Los municipios elevan al máximo posible el suelo urbanizable donde se levantan multitud de viviendas ante el alza de la demanda. Los máximos incrementos, entre 100 y $200 \%$, se registran en el Este y Sur metropolitanos, y los menores en territorios ya sobradamente saturados de segundas residencias, como la Sierra Central y el Oeste metropolitano. El panorama en 2001 reproduce, pero atenúa, los contrastes de treinta años antes. Así, exceptuada la capital, los territorios que destacan por número de segundas residencias, Sierra Central y Oeste metropolitano, concentran el $41 \%$ del total de la Comunidad, siendo treinta años antes el 54\%. Por el contrario, los de menores efectivos, Este y Norte metropolitanos y periferia del Noreste, reúnen ahora el 14\%, cuando en 1970 era el 7,5\%.

Los resultados a nivel municipal permiten precisar más sobre la dinámica seguida por la segunda residencia entre 1970 y 2001 y revelan comportamientos que las unidades territoriales mayores disimulan (MAPA 2). Así, en 1970, sólo 26 municipios $(14,6 \%)$ cuentan con menos de diez viviendas secundarias, la mitad de ellos localizados en la Sierra Norte. A partir de ese momento y hasta 2001, el 58\% de los municipios madrileños aumentan inin- 
Mapa 2. Dinámica de las viviendas secundarias (1970-2001)

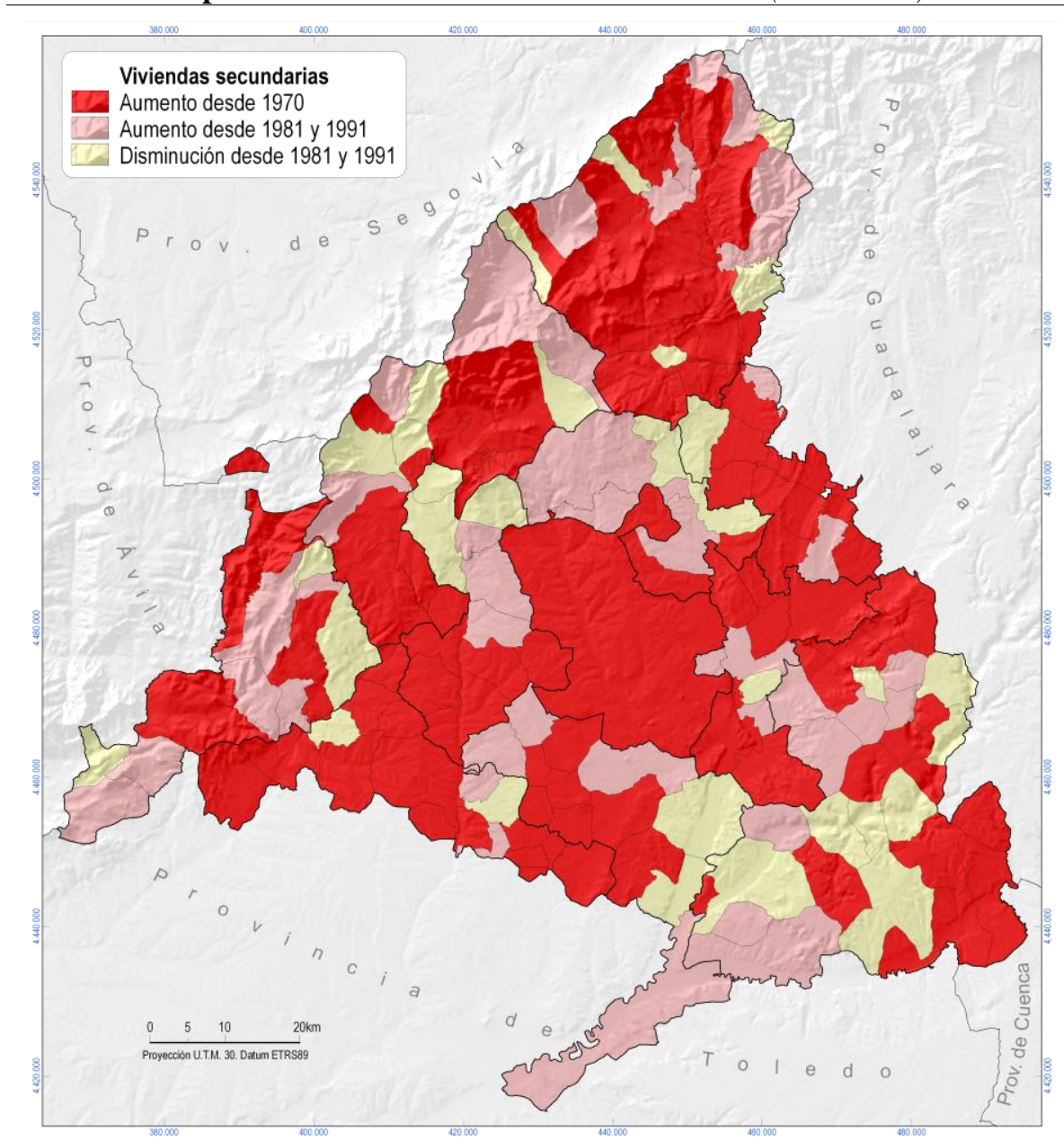

FUENTE: Censos (1970-2001)

terrumpidamente sus viviendas secundarias, mientras que un $24 \%$ presentan avances y retrocesos en su dinámica hasta 1991, para reconocerse positiva a partir de entonces. Finalmente, el $18 \%$ restante experimentan descensos en el número de secundarias, algunos ya desde los años ochenta (Moraleja de Enmedio en el Suroeste metropolitano, Ciempozuelos en el Sur metropolitano y Chinchón, Perales y Tielmes en la periferia del Sureste), extendiéndose la tendencia a partir de los noventa a otros muchos, debido especialmente a la transformación de las viviendas secundarias en principales. Aunque los municipios con pérdidas de secundarias se dispersan por todo el territorio 
madrileño se observan algunas concentraciones en la Sierra Central, en el Norte y Oeste metropolitanos y en la periferia del Sureste.

\section{III.4. El protagonismo de la vivienda secundaria en el parque residen- cial $(1970-2001)$}

La representación de las viviendas secundarias en el conjunto del parque residencial es uno de los indicadores que, entre otros, aportan una imagen de la significación turística de los municipios ${ }^{6}$, dándose casos donde la segunda residencia no sólo es mayoritaria, sino la protagonista indiscutible del espacio construido, con las connotaciones de todo tipo que ello conlleva.

Aunque en el conjunto de la comunidad madrileña la presencia de las viviendas secundarias ha aumentado desde 1970, a nivel de unidad territorial y, sobre todo, municipal se descubren suficientes contrastes que invitan a insistir más en este punto. La construcción de nuevas viviendas, su adquisición como bien de uso o de inversión, la ruina del parque residencial de mayor antigüedad, la transformación de viviendas principales en secundarias y de secundarias en principales, o la existencia de viviendas vacías, hacen variar la representación de las segundas residencias a lo largo del tiempo. En 1970 las viviendas secundarias ocupan más de la mitad del parque residencial en el $11 \%$ de los municipios madrileños, diez años más tarde en el $45 \%$, para descender en 1991 al $43 \%$ y en 2001 al 39\% (CUADRO 10).

Cuadro 10. Número de municipios según la representación de la segunda residencia en el parque residencial (1970 y 2001)

\begin{tabular}{lrrrrrrrrr}
\hline \multicolumn{1}{c}{ NUTS } & \multicolumn{2}{c}{ Total } & \multicolumn{2}{c}{1970} & \multicolumn{2}{c}{1981} & \multicolumn{2}{c}{1991} & \multicolumn{2}{c}{2001} \\
\cline { 3 - 10 } & mun. & $\% S R$ & $\% S R$ & $\% S R$ & $\% S R$ & $\% S R$ & $\% S R$ & $\% S R$ & $\% S R$ \\
& & $25-49$ & +50 & $25-49$ & +50 & $25-49$ & +50 & $25-49$ & +50 \\
\hline Municipio Madrid & 1 & - & - & - & - & - & - & - & - \\
Norte Metropolitano & $6 / 7$ & 1 & - & 2 & - & 1 & 1 & - & - \\
Este Metropolitano & 10 & - & - & - & - & - & - & - & - \\
Sur Metropolitano & 12 & - & - & - & - & 1 & - & - & - \\
Oeste Metropolitano & 11 & 4 & 3 & 3 & 4 & 3 & 2 & 2 & - \\
Sierra Norte & 44 & 21 & 2 & 7 & 33 & 10 & 31 & 8 & 34 \\
Sierra Central & 17 & 4 & 10 & 1 & 15 & 3 & 13 & 7 & 9 \\
Sierra Sur & 14 & 9 & 2 & 3 & 11 & 4 & 9 & 2 & 11 \\
Noreste Comunidad & 12 & 1 & - & 5 & 2 & 5 & 3 & 6 & 4 \\
Sureste Comunidad & 33 & 8 & 2 & 13 & 9 & 8 & 13 & 13 & 8 \\
Suroeste Comunidad & 18 & 7 & 2 & 4 & 7 & 6 & 6 & 6 & 5 \\
\hline Comunidad & $178 / 179$ & 55 & 21 & 38 & 81 & 41 & 78 & 44 & 71 \\
\hline
\end{tabular}

FUENTE: Elaborado a partir de INE: Censos de Población y Vivienda (nivel municipal;. Norte Metropolitano añade el municipio de Tres Cantos al segregarse de Colmenar Viejo en 1991).

\footnotetext{
${ }^{6}$ Este indicador está cartografiado para 1970 por VALENZUELA (1976) y para 1981 por Chuvieco / AldecoA (1983). VAlenzuela (1996 y 2003) emplea también el índice de especialización turístico-residencial para 1970 y 2001.
} 
En 1970 ningún municipio entre los metropolitanos tiene predominio de las segundas residencias en su parque residencial. Por el contrario, la Sierra Central concentran la mitad de los municipios madrileños con presencia mayoritaria de secundarias. Éste es el territorio de mayor tradición turística por la atracción del Guadarrama y sus buenas condiciones de accesibilidad, al tiempo que registra el mayor número de urbanizaciones localizadas fuera de los núcleos urbanos (CUADRO 11). El mayor protagonismo de residencias secundarias recae en Soto del Real, donde representan más de las tres cuartas partes, aunque llegan a superar la mitad en Alpedrete, Becerril, Cercedilla, Collado Mediano, El Escorial, Guadarrama, Manzanares el Real, Navacerrada y Valdemorillo. La mitad de las urbanizaciones de este territorio se concentran en El Escorial, cuyos chalés suponen el 37\% de las secundarias del municipio.

Cuadro 11. Número de municipios con urbanizaciones en la periferia de los núcleos urbanos

\begin{tabular}{lrrrr}
\hline \multirow{2}{*}{ NUTS } & \multicolumn{2}{c}{ Nomenclátor de 1970 } & \multicolumn{2}{c}{ Nomenclátor de 1986 } \\
\cline { 2 - 5 } & $N^{o}$ de municipios & Urbanizaciones & $N^{\circ}$ de municipios & Urbanizaciones \\
\hline Municipio Madrid & - & - & - & - \\
Norte Metropolitano & 3 & 6 & 4 & 10 \\
Este Metropolitano & 1 & 1 & 3 & 12 \\
Sur Metropolitano & 1 & 1 & 3 & 6 \\
Oeste Metropolitano & 1 & 5 & 10 & 50 \\
Sierra Norte & - & - & 15 & 37 \\
Sierra Central & 3 & - & 13 & 48 \\
Sierra Sur & 1 & - & 6 & 10 \\
Nordeste Comunidad & - & 1 & 5 & 5 \\
Sudeste Comunidad & 1 & - & 11 & 19 \\
Sudoeste Comunidad & - & 23 & 79 & 215 \\
\hline Comunidad & 11 & - & 79 & 18 \\
\hline
\end{tabular}

FUENTE: Elaborado a partir de INE, Nomenclátor (1970) y Comunidad de Madrid, Nomenclator (1986)

En los restantes municipios la presencia de la segunda residencia es mucho menor, sin llegar en ninguno a superar las tres cuartas partes del parque residencial y siendo pocos donde pasan de la mitad. En el Oeste metropolitano se imponen en los municipios del piedemonte serrano de Galapagar, Hoyo de Manzanares y Torrelodones, localizándose en el primero todas las urbanizaciones instaladas en esta unidad. En los otros territorios serranos la emigración les hace perder efectivos y, aun sin contar apenas con urbanizaciones, la segunda residencia domina por la transformación de las antiguas viviendas principales en secundarias en los municipios de Santa María de la Alameda y Valdemaqueda, cercanos al cordal del Guadarrama en la Sierra Sur, y en Canencia y Navalafuente, ubicados al pie del cordal en la Sierra Norte. En los sectores periféricos del Sureste y Suroeste de la Comunidad 
también hay municipios con mayoría de secundarias, en el primero los de Aldea del Fresno y El Álamo, localizados en el entorno del río Alberche, y en el segundo los de Nuevo Baztán y Olmeda de las Fuentes, instalados en la campiña del Henares, donde la urbanización Eurovillas concentra el 92\% de las viviendas secundarias de Nuevo Baztán.

Los efectos del fortísimo crecimiento de la vivienda secundaria durante los años setenta se refleja en su predominio en casi la mitad de los municipios madrileños en 1981, siendo las 747 urbanizaciones y sus 39.000 chalés construidos, contabilizados a finales de la década, fundamentales en los resultados (CUADRO 12).

Cuadro 12. Municipios con urbanizaciones de segunda residencia en la periferia de los núcleos urbanos en 1979

\begin{tabular}{lrrrrr}
\hline \multicolumn{1}{c}{ NUTS } & $N^{o}$ de & Urbanizaciones & $\begin{array}{r}\text { Chalés } \\
\text { terminados }\end{array}$ & $\begin{array}{r}\text { Chalés en } \\
\text { construcción }\end{array}$ & $\begin{array}{r}\text { Parcelas } \\
\text { sin edificar }\end{array}$ \\
\hline Municipio Madrid & - & - & - & - & - \\
Norte Metropolitano & 5 & 52 & 2.915 & 227 & 2.199 \\
Este Metropolitano & 3 & 11 & 166 & 23 & 88 \\
Sur Metropolitano & 3 & 8 & 457 & 129 & 118 \\
Oeste Metropolitano & 9 & 150 & 9.770 & 642 & 9.020 \\
Sierra Norte & 18 & 47 & 2.698 & 114 & 1.550 \\
Sierra Central & 16 & 223 & 10.901 & 355 & 8.172 \\
Sierra Sur & 13 & 66 & 4.902 & 349 & 1.200 \\
Noreste Comunidad & 8 & 21 & 483 & 55 & 218 \\
Sureste Comunidad & 24 & 86 & 3.726 & 114 & 1.550 \\
Suroeste Comunidad & 14 & 83 & 2.984 & 161 & 968 \\
\hline Comunidad & 113 & 747 & 39.002 & 2.356 & 27.624 \\
\hline Fur
\end{tabular}

FUENTE: Elaborado a partir de COPLACO (1980)

Son las tres unidades territoriales serranas quienes registran los mayores cambios, alcanzando la presencia mayoritaria de residencias secundarias a más del $75 \%$ de los municipios, y llegando en el sector central al $88 \%$. Es más, ahora, en muchos municipios las secundarias se imponen en más de las tres cuartas partes del parque residencial. Lo hacen en la Sierra Central los de Soto del Real, Becerril y Collado Mediano, estando localizadas en las urbanizaciones buena parte de las segundas residencias, el $70 \%$ de las de Soto y el $44 \%$ de las de Becerril; en la Sierra Sur las secundarias protagonizan el parque residencial en Santa María de la Alameda, Valdemaqueda y Pelayos de la Presa, donde las promociones acogen a más de la mitad, y en la Sierra Norte, con buena parte de las urbanizaciones en condición de ilegalidad, son Navalafuente, Alameda del Valle y Venturada, ubicadas el 53\% de las secundarias en urbanizaciones en el primero y el $77 \%$ en el último (CUADRO $13)$.

En los restantes territorios los municipios con predominio de la segunda 
residencia son menos y menos aún aquellos con presencia casi exclusiva. Se imponen en el $40 \%$ de los municipios de la periferia del Suroeste, pero sólo en Batres superan el 75\% del parque residencial. En el también periférico del Sureste, que concentra la mayor parte de las urbanizaciones ilegales de la Comunidad, la mayoría de secundarias alcanza al $27 \%$ de sus municipios, siendo en Nuevo Baztán donde superan las tres cuartas partes ${ }^{7}$. Aunque en el Oeste metropolitano y en la periferia del Noreste hay municipios con presencia mayoritaria de la segunda residencia, en ninguno alcanzan el $75 \%$ del parque, a pesar de contar con buen número de urbanizaciones. Es el caso de Collado Villalba, en el Oeste metropolitano, que destaca en el conjunto de la Comunidad por el número de viviendas secundarias (6.804) y por el de urbanizaciones (36), sólo superado en este último caso por el de Pozuelo (77). También son numerosas las actuaciones inmobiliarias en Galapagar (30), que concentran la mitad de las secundarias del municipio, las de Hoyo de Manzanares (21) donde llegan a representar más de la mitad y las de Villanueva de la Cañada (8) que acogen al 77\%. Y en el Noreste de la Comunidad también las urbanizaciones hacen que la segunda residencia se imponga en la mitad del parque residencial de los municipios de Ribatejada y Talamanca, localizándose en ellas el $51 \%$ de las secundarias en el caso del primero y el $25 \%$ en el segundo.

Cuadro 13. Municipios con urbanizaciones ilegales en 1984

\begin{tabular}{|c|c|c|c|c|}
\hline \multirow[b]{2}{*}{ NUTS } & \multirow{2}{*}{$\begin{array}{r}N^{o} \text { de munici- } \\
\text { pios }\end{array}$} & \multicolumn{3}{|c|}{ Urbanizaciones ilegales } \\
\hline & & Anteriores a 1980 & $\begin{array}{r}\text { Entre } 1980 \text { y } \\
1984\end{array}$ & Total \\
\hline Municipio Madrid & - & - & - & - \\
\hline Norte Metropolitano & 2 & 3 & 2 & 5 \\
\hline Este Metropolitano & 4 & 6 & 3 & 9 \\
\hline Sur Metropolitano & 2 & 2 & - & 2 \\
\hline Oeste Metropolitano & 2 & 2 & - & 2 \\
\hline Sierra Norte & 12 & 17 & 4 & 21 \\
\hline Sierra Central & 2 & 2 & 3 & 5 \\
\hline Sierra Sur & 3 & 3 & 1 & 4 \\
\hline Noreste Comunidad & 8 & 3 & 17 & 20 \\
\hline Sureste Comunidad & 12 & 25 & 3 & 28 \\
\hline Suroeste Comunidad & 6 & 5 & 3 & 8 \\
\hline Comunidad & 52 & 68 & 36 & 104 \\
\hline
\end{tabular}

FUENTE: Elaborado a partir de COMUNIDAD DE MADRID (1984)

En 1991 el descenso de la representación de la vivienda secundaria que se observa en el conjunto de la Comunidad se traduce a buena parte del territo-

\footnotetext{
${ }^{7}$ El número de chalés terminados en las urbanizaciones de Nuevo Baztán y Batres que aporta el estudio de Coplaco de 1979 es superior a las viviendas secundarias que aparecen en el censo de 1981. Quizá porque en la última fecha algunas aparezcan registradas como vacías.
} 
rio. De esta tónica general se descuelgan los territorios periféricos del Sureste y del Nordeste. En el primero, la mayoría de secundarias alcanza ahora al 40\% de sus municipios, donde sólo en Ambite superan las tres cuartas partes del parque residencial. En el segundo, la presencia mayoritaria de secundarias aparece en el 25\% de sus municipios, siendo Fresno de Torote el único donde se imponen de manera contundente ${ }^{8}$. Dentro de esta dinámica hay que añadir el municipio de Algete, en el Norte metropolitano, que ahora se incorpora a los municipios con mayoría de secundarias. En los restantes territorios, aunque hay municipios que mantienen e incluso aumentan la representación de las segundas residencias, y otros se añaden ahora, son más aquellos en los que pierde protagonismo. En los sectores serranos aunque desciende el número de municipios con predominio de secundarias, todavía se imponen en más de la mitad, llegando en algunos a protagonizar el parque residencial. Así, en la Sierra Norte siguen siendo cinco los municipios especializados, repitiendo sólo Venturada e incorporándose ahora Garganta de los Montes, Gargantilla, Horcajo de la Sierra y Villavieja del Lozoya; en la Sierra Central se mantiene Soto del Real y se añaden El Boalo y Manzanares el Real; y en la Sierra Sur repiten Pelayos de la Presa y Santa María de la Alameda y se incorpora Rozas de Puerto Real. En el Suroeste de la Comunidad sólo Batres se mantiene como municipio especializado.

Durante la década de 1990 sigue descendiendo en la Comunidad el número de municipios con presencia mayoritaria de viviendas secundarias, siendo la transformación de éstas en principales el factor más significativo. Sólo escapan de esta dinámica los sectores Norte y Sur de la Sierra y, en menor medida, la periferia Noreste al añadir algún municipio a esta categoría. Pero el resultado en 2001 del protagonismo de la vivienda secundaria en el parque residencial se torna más significativo a nivel municipal (MAPA 3).

La mayor concentración de municipios con mayoría de secundarias se observa en los ámbitos serranos, especialmente en los sectores Norte y Sur, pues el Central ha perdido algunos que ostentaban este rango diez años antes. Destacan, asimismo, aunque puntualmente, municipios ubicados en los extremos de las restantes unidades, tal y como se apreciaba en las décadas pasadas, manteniéndose unos, incorporándose otros o desapareciendo algunos. Sin embargo, atendiendo a los especializados en segunda residencia, por representar más del $75 \%$ de su parque residencial, su distribución por el te-

\footnotetext{
${ }^{8}$ En el Nordeste contrastan las promociones ilegales de los primeros años de la década que detecta COPLACO (1984) con las escasas urbanizaciones que registra el NOMENCLÁTOR (1986). Tras analizar la información se observa que muchas ilegales presentan bajo o muy bajo grado de consolidación, están ocupadas por chamizos o en donde se ha suspendido la concesión de licencias. Quizás en 1986 ya se han desmantelado o no se consideran urbanizaciones.
} 
rritorio sufre modificaciones. Ahora se concentran más en la Sierra Norte y en la Sur, mientras que los restantes territorios, si los tenían, los han perdido, aunque cabe destacar que ya en ningún municipio de los territorios metropolitanos las segundas residencias son las protagonistas casi en exclusividad del parque residencial.

Mapa 3. Protagonismo de la vivienda secundaria en el parque residencial (2001)

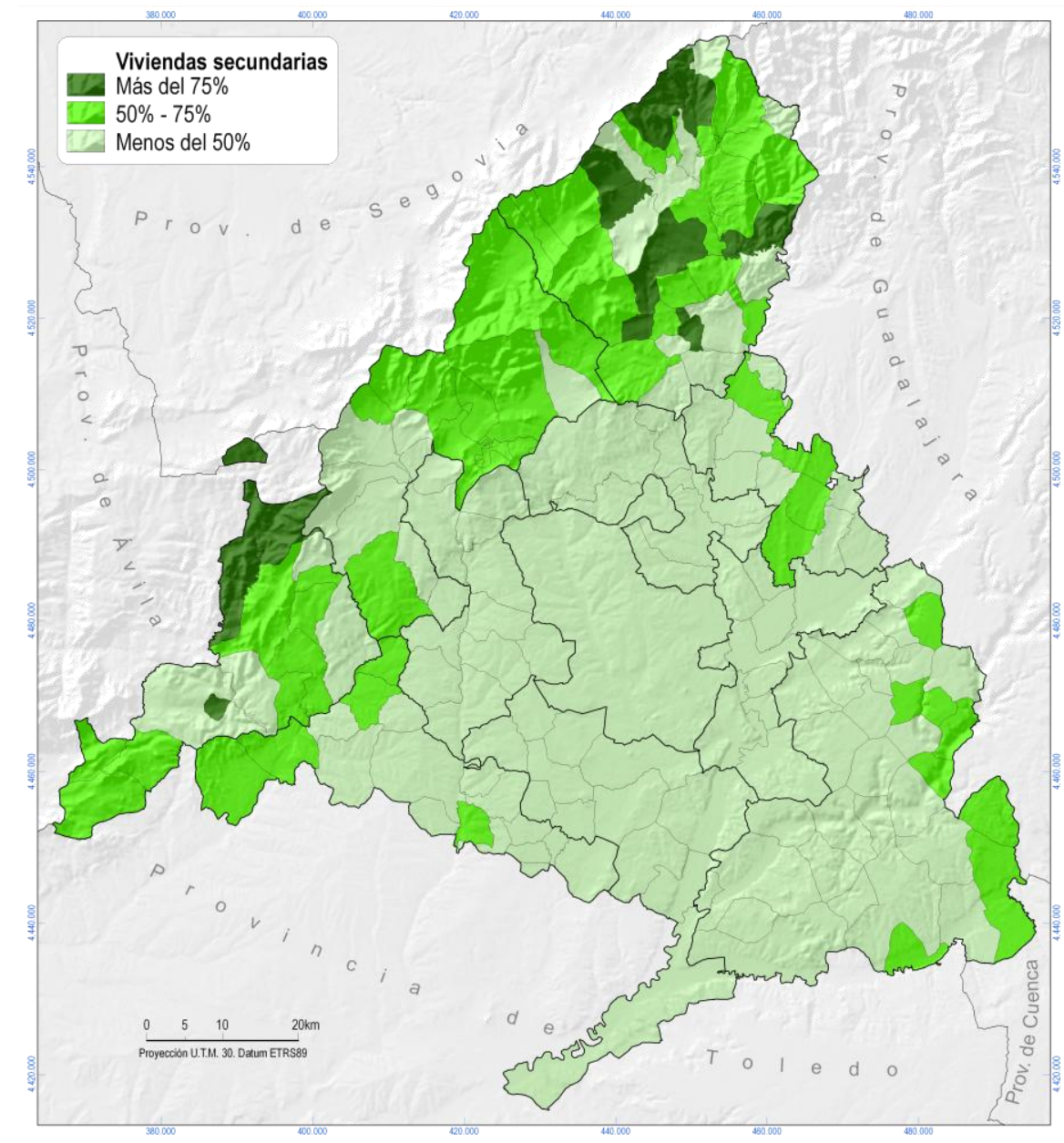

FUENTE: Censos (1970-2001)

De los 71 municipios en los que las viviendas secundarias representan más de la mitad de su parque residencial en 2001, y que alcanzan al $40 \%$ de los municipios madrileños, la mayoría (39) mantienen esta situación desde 1981, 
algunos (10) la sustentan desde 1970, otros (9) la adquieren a partir de 1991 y los menos (5) la consiguen en 2001. Los restantes, pudieron ostentarla en algunos momentos y perderla en otros, sin mostrar, en consecuencia, continuidad. Así, pues, los diez municipios más veteranos, esto es, los que prolongan desde 1970 la mayoría de segundas residencias en el parque residencial son los de Navalafuente (Sierra Norte), Navacerrada, Becerril, Manzanares el Real y Valdemorillo (Sierra Central), Santa María de la Alameda y Valdemaqueda (Sierra Sur) y Nuevo Baztán, Olmeda de las Fuentes y Ambite (periferia del Sureste), siendo, entre ellos, los de Navalafuente, Santa María de la Alameda y Valdemaqueda los que han visto como la vivienda secundaria progresivamente se iba adueñando del parque residencial hasta llegar a representar más de las tres cuartas partes. El caso opuesto es el de los municipios que sólo desde 2001 cuentan con mayoría de secundarias. Son los de La Cabrera, Puebla de la Sierra y Rascafría (Sierra Norte), Daganzo (periferia del Noreste) y Villanueva de Perales (periferia del Suroeste), entre los que La Cabrera es el único donde la segunda residencia se muestra casi en exclusiva.

\section{III.5. El parque residencial en la primera década del siglo XXI}

A partir de 2001 las fuentes estadísticas publicadas no aportan información del parque residencial por tipos de vivienda. Sin embargo, son interesantes las que facilita el Instituto de Estadística de la Comunidad de Madrid con datos de los Ministerios de Fomento y de Economía y Hacienda. La dinámica constructiva de la primera década del siglo XXI que se aprecia en la Estadística de Edificios y Viviendas muestra que el número total de viviendas terminadas aumenta durante los primeros años hasta alcanzar el máximo en 2004 (59.962), superando el pico que supuso 1997 (53.753). Desde entonces,

y coincidiendo con el inicio de la crisis inmobiliaria, las viviendas terminadas sufren un descenso, mantenido al principio, pero no así a partir de 2007, con los efectivos muy disminuidos en 2009 (38.610) (GRÁFICO 3).

Los encargos de dirección de obra dan información sobre la tipología morfológica de los edificios residenciales, distinguiendo las viviendas unifamiliares de las ubicadas en edificios plurifamiliares. Aunque la vivienda unifamiliar ya no es exclusiva de la segunda residencia, si es común que las nuevas viviendas de uso turístico adquieran esta tipología. Y si se observa la dinámica de construcción de ambos tipos, similar en el ritmo temporal, a partir de la crisis el descenso anual de las unifamiliares es superior al de las localizadas en edificios en altura, explicable por la mayor dificultad para las promotoras de colocar en el mercado este tipo de viviendas, tanto como segunda residencia o principal, dado su mayor precio (GRÁFICO 4). 
Las licencias municipales solicitadas permiten conocer las viviendas que se pretenden levantar cada año en los distintos territorios madrileños. El monto de viviendas a construir en el periodo 2000-2009 se acerca al medio millón y aunque la diferencia entre ambos quinquenios no es significativa (239 mil y 225 mil) lo es, sin embargo, su distribución por la Comunidad. Los territorios que se muestran más proclives en erigir viviendas son la capital, donde las licencias de obras de los PAUS elevan la cifra especialmente en los primeros años, al igual que en los sectores metropolitanos, en parte debido a estar todavía en construcción las actuaciones sobre los consorcios urbanísticos, destacando el Sur que acumula seis de ellos. La crisis del sector inmobiliario a partir de 2005 se deja sentir en todos los territorios, excepto en los periféricos del Suroeste y Sureste, en el primero gracias a las licencias de los municipios de Arroyomolinos y Navalcarnero que acumulan el 67\% de las licencias (GRÁFICO 5).

Gráfico 3. Viviendas terminadas en la Comunidad de Madrid

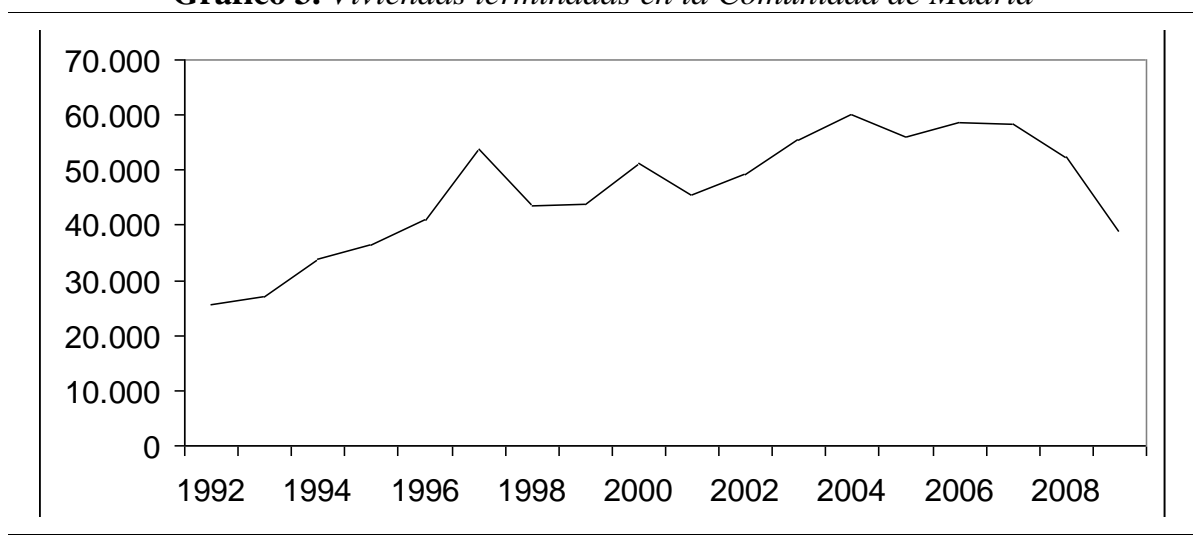

FuENTE: Ministerio de Fomento e Instituto de Estadística de la Comunidad de Madrid.

Gráfico 4. Viviendas terminadas en la Comunidad de Madrid según tipo de edificio

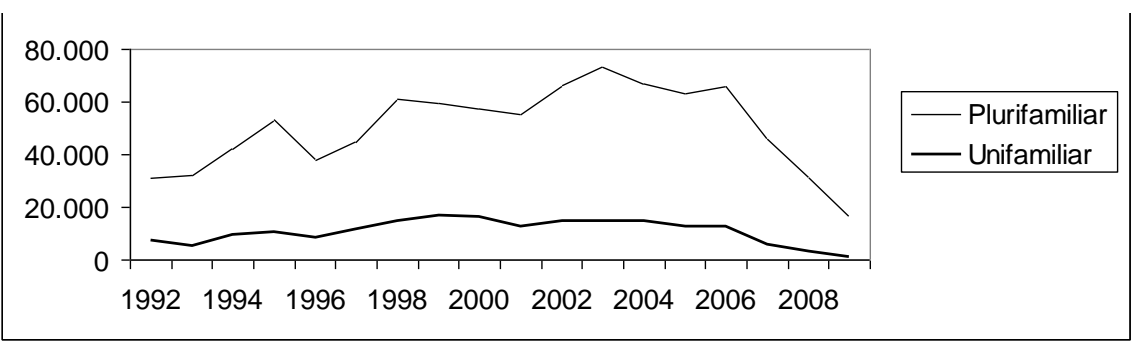

FUENTE: Ministerio de Fomento e Instituto de Estadística de la Comunidad de Madrid. 
Gráfico 5. Viviendas a construir en las NUT's de la Comunidad de Madrid

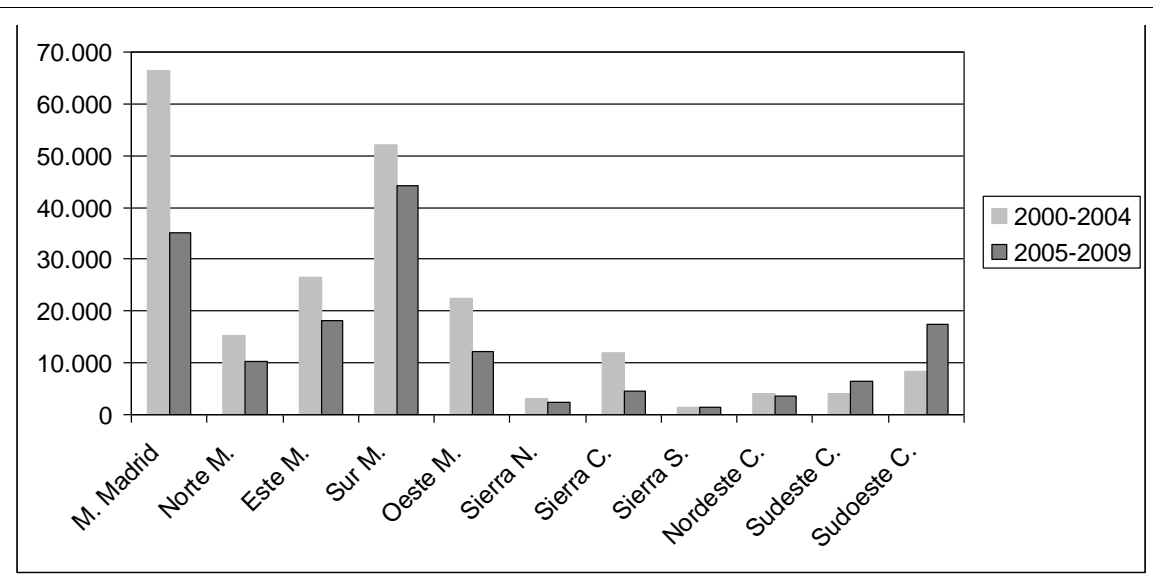

FuENTE: Ministerio de Fomento e Instituto de Estadística de la Comunidad de Madrid.

El Catastro Inmobiliario Urbano permite conocer el valor catastral para uso residencial de los distintos territorios de la Comunidad en una serie que va de 2003 a 2009. Se observa que este valor en relación al del total de las unidades urbanas estaba por encima del $70 \%$ al inicio de la serie en la Sierra Central $(75,5 \%)$, la Sierra Sur $(74,5)$ y la periferia del Sureste (71). En 2009, el primer puesto lo ocupa la Sierra Sur (78\%), seguido de la Sierra Central (77) y de la Sierra Norte (73) que partía de una representación del 65\%. Se pone, pues, en evidencia la función eminentemente residencial de los sectores serranos en 2009. En los restantes territorios madrileños disminuye en estos años la participación del valor catastral de uso residencial, salvo en el Este metropolitano que la sube dos puntos, llegando al 59\%, aunque no sobrepasa del séptimo puesto.

\section{CONCLUSIONES}

Vistos los resultados del estudio se pueden apuntar algunas conclusiones. Por un lado, cabe decir que el Censo de Población y Vivienda se muestra la fuente más idónea para conocer el monto y la distribución territorial de la vivienda secundaria. Ahora bien, las variadas razones que encubren su existencia, desde la facultad para asumir distintos usos hasta su adquisición como bien inmobiliario de inversión, impiden poder considerarlas en exclusividad como forma de alojamiento turístico, por lo que su estudio no permite aportar más allá de una aproximación al fenómeno.

Por otro lado, y asumidas estas consideraciones, la investigación sobre la comunidad madrileña pone de manifiesto, entre otras cosas, lo siguiente: La 
dinámica del parque de segunda residencia sigue los ritmos del mercado inmobiliario y su incremento sobrepasa el de la vivienda principal en las coyunturas alcistas. El número de viviendas secundarias aumenta hasta 2001, multiplicando casi por dos las de diez años antes y alcanzar la relación por mil habitantes más alta de su historia. En su distribución territorial siguen primando los ámbitos de mayor tradición, la Sierra, aunque desde los años noventa se asiste a un descenso de las secundarias debido a su transformación en viviendas principales, fenómeno no exclusivo de estos territorios, como se observa especialmente en la periferia del Sudeste de la Comunidad, donde incluso el fenómeno se adelanta diez años. El protagonismo de la residencia secundaria en el parque residencial se ha mantenido en los municipios serranos y, desde la década de 1980, también en otros localizados en el borde de la Comunidad. Los municipios especializados por representar las secundarias más de las tres cuartas partes del parque residencial se localizan en 2001 casi en su totalidad en la Sierra Norte y, en menor medida, en la Sierra Sur, habiendo desaparecido de esta categoría los que anteriormente la ostentaban en el resto del territorio madrileño.

\section{BIBLIOGRAFÍA}

CANTO FRESNO, C. (1981): La vertiente meridional de la Sierra de Gredos como un área de recreo y residencia secundaria de la población madrileña. Tesis doctoral, Universidad Complutense de Madrid.

CANTO FRESNO, C. (1983a): «Localización de residencias secundarias y modelo territorial. El ejemplo de Madrid» en Espacio, sociedad y economía en la Comunidad Autónoma de Madrid (ASOCIACIÓN MADRILEÑA DE CIENCIA REGIONAL). Madrid, 97-119.

CANTO FRESNO, C. (1983b): «Presente y futuro de las residencias secundarias en España». Anales de Geografía de la Universidad Complutense de Madrid, $\mathrm{n}^{\circ} 3$, 83-103.

CANTO FRESNO, C. (1987): «Esquema interpretativo de la producción de espacios turísticos-residenciales madrileños». Anales de Geografía de la Universidad Complutense de Madrid, $\mathrm{n}^{\circ}$ 7, 389-398.

CANTO Fresno, C. (1994): «La periferia metropolitana de Madrid como espacio de ocio: una nueva ruralidad». Espacio y Sociedad, no 11, 131-147.

COMUNIDAD DE MADRID (1984): Urbanizaciones ilegales. Programa de actuación y catálogo, Madrid, Comunidad de Madrid.

COPLACO (1980): Estudio sobre las urbanizaciones de segunda residencia en la provincia de Madrid. Ministerio de Obras Públicas y Urbanismo.

CóRDOBA, V.; PeIRET, A.; SANTOS, L. (2000): «La segunda residencia en el medio rural de Castilla y León», en: VII Congreso de Desarrollo Rural, Soria, 11451167.

CORTINA, F.; MARTíNEZ, A.; VARELA, B. (2002): «Aproximación a la investigación del alojamiento privado de uso turístico», Estudios Turísticos, nº 151, 87-97. 
CORTIZO, T. (2007): «La promoción de vivienda de ocio en Ribadesella. Asturias», en VIII Coloquio y Jornadas de Campo de Geografía Urbana. Acta. Ponencias y Comunicaciones. Palma de Mallorca. AGE-Grupo de Geografía Urbana, 313329.

Chuvieco, E.; AldecoA, M. A. (1983): «La segunda residencia y el medio rural». El Campo, $\mathrm{n}^{\circ}$ 90, 93-104.

Delgado, C. (2007): «La función residencial secundaria en Cantabria como generadora de nuevos desequilibrios territoriales» en VIII Coloquio y Jornadas de Campo de Geografía Urbana. Acta. Ponencias y Comunicaciones. Palma de Mallorca. AGE-Grupo de Geografía Urbana, 331-348.

Delgado, C. (2008): «Viviendas secundarias y turismo residencial como agente de urbanización y segregación territorial en Cantabria». Scripta Nova. Revista Electrónica de Geografía y Ciencias Sociales. Barcelona, vol. XII, nº 269. En línea: http://www.ub.es/geocrit/sn/sn/-316.htm

Delgado, C.; Gil De ArRiBA, C.; Hortelano, L.; PlazA, J. (2005): «Terciarización turística y difusión urbana en un espacio rural de montaña. La segunda residencia en el sector central de la cordillera cantábrica» en Turismo residencial y cambio social (MAZÓn, T.; AlEDO, A., eds.). Alicante, Universidad de Alicante, 157-172.

FRAGUELl SANSBELló, R. (1984): Turisme residencial i territorio. La segona residència a la regió de Girona, Girona, L’Eix Editorial

Gago, V. (1983): «Vivienda y crisis de la construcción en Madrid». Revista de Obras Públicas, n 3212, 263-274.

GARCÍA ANDREU, H. (2005): «Un acercamiento al concepto de turismo residencial» en Turismo residencial y cambio social (MAZÓN, T.; AlEDO, A., eds.). Alicante, Universidad de Alicante, 55-69.

García, J. A.; Cebrián, F.; PANAdero, M. (2008): "El turismo de segunda residencia en el interior peninsular". Scripta Nova. Revista Electrónica de Geografía y Ciencias Sociales. Barcelona, vol. XII, no 270. En línea: http://www.ub.es/geocrit/sn/sn/-316.htm

GonZÁlez REverté, F. (2005): “La segunda residencia en Cataluña. Caracterización, impactos y retos" en Turismo residencial y cambio social (MAZÓN, T.; AlEDO, A., eds.). Alicante, Universidad de Alicante, 73-104.

HuETE, R. (2008): «Tendencias del turismo residencial. El caso del Mediterráneo español». El Periplo Sustentable, no 14, 65-87.

HuETE, R. (2010): «Opiniones y actitudes ante el turismo residencial en el sur de la Comunidad Valenciana». Pasos, ${ }^{\circ}$ 14, 445-461.

Huete, R.; MANTECón, A.; MAZÓn, T. (2008): «¿De qué hablamos cuando hablamos de turismo residencial?». Cuadernos de Turismo, $\mathrm{n}^{\mathrm{o}}$ 22, 101-121.

LÓPEZ COLÁs, J. (2003): «La residencia secundaria en España: estudio territorial de su uso y tenencia». Tesis doctoral, Universidad de Barcelona. En línea: http://www.tdx.cesca.es

LóPez ColÁs, J.; Módenes CABrerizo, J. A. (2004): «Vivienda Secundaria y residencia múltiple en España: una aproximación socioeconómica». Scripta Nova. Revista Electrónica de Geografía y Ciencias Sociales. Barcelona, vol. VII, $\mathrm{n}^{\mathrm{o}}$ 178. En línea: http://www.ub.es/geocrit/sn/sn/-316.htm. 
Martínez, F. J.; PAUls, A. J.; SolsonA, J. (2003): «Las viviendas familiares y su uso turístico en la Comunidad valenciana». Estudios Turísticos, n ${ }^{\circ} 155-156,150$ 177.

MAZÓn, T.; AlEDo, A. (2005a): «El dilema del turismo residencial: ¿turismo o desarrollo inmobiliario?» en Turismo residencial y cambio social (MAZÓN, T.; AlEDO, A., eds.). Alicante, Universidad de Alicante, 13-31.

MAZÓn, T.; AlEDO, A. (2005b): «Los límites del turismo residencial: el caso de Torrevieja». Estudios Turísticos, no $165,77-95$.

MiLlán ESCRICHE, M. (2005): «La eclosión del turismo residencial en la región de Murcia como estrategia para la diversificación funcional de su territorio» en $\mathrm{Tu}$ rismo residencial y cambio social (MAZÓn, T.; AlEDO, A., eds.). Alicante, Universidad de Alicante, 139-156.

MATEU I LlADÓ, J. (2003): «Turismo residencial y dispersión urbana en Mallorca (Illes Balears): un ensayo metodológico en el municipio de Pollensa». Estudios Turísticos, $\mathrm{n}^{\circ} 155-156,197-218$.

Miranda Montero, A. (1981): Geografía del ocio de la Provincia de Valencia. La segunda residencia. Tesis doctoral, Universidad de Valencia.

NAREDO, J. M. (1996): La burbuja inmobiliario-financiera en la coyuntura económica reciente (1985-1995). Madrid, Siglo XXI.

NAVALÓN, R. (1995): Planeamiento urbano y turismo residencial en los municipios litorales de Alicante, Valencia, Generalitat Valenciana.

NAVARRO, E. (2007): «La expansión y exportación del modelo residencial-turístico a espacios no costeros: el caso de la provincia de Málaga» en VIII Coloquio y Jornadas de Campo de Geografía Urbana. Acta. Ponencias y Comunicaciones. Palma de Mallorca. AGE-Grupo de Geografía Urbana, 371-382.

ORTEGa VAlCARCEL, J. (1975): Residencias Secundarias y espacio de ocio en España, Valladolid, Universidad de Valladolid.

PALlARÉS, M. (1991): La residència secundaria de la població de Barcelona i de la seva Àrea Metropolitana (1985-1990). Barcelona, Institut d'Estudis Metropolitans de Barcelona.

PARREÑO, J. M. (2007): «Turismo residencial de europeos y consecuencias inmobiliarias en Canarias» en VIII Coloquio y Jornadas de Campo de Geografía Urbana. Acta. Ponencias y Comunicaciones. Palma de Mallorca. AGE-Grupo de Geografía Urbana, 383-398.

Pozo Rivera, E.; García PAlOMARes, J. C. (2009): «Inmigración y cambio demográfico en la región metropolitana madrileña entre 1996 y 2006». Anales de Geografía de la Universidad Complutense de Madrid, $\mathrm{n}^{\circ}$ 1, 111-138.

RAYA MEllado, P. (2003): «El turismo residencial en el litoral andaluz». Estudios Turísticos, $\mathrm{n}^{\mathrm{o}}$ 155-156, 179-196.

REQUEJO, J. (2007): «Turistas: del concepto legal a la compleja realidad del actual panorama español». Estudios Turísticos, n 172-173, 147-157.

Roch, F. (2002): «Agentes sociales y tendencias urbanísticas: hegemonía y pérdida de urbanidad», Ciudades para un futuro más sostenible. En línea: http://habitat.aq.upm.es/boletin/n29/afroc1.html 
RODRÍGUEZ AlONSO, R. (2004): «Infrautilización del parque de viviendas en España: aparición de viviendas vacías y secundarias», Ciudades para un futuro más sostenible. En línea: http://habitat.aq.upm.es/boletin/n29/arrod3.html

RODRÍGUEZ RODRÍGUEZ, V. (2004): «Turismo residencial y migración de jubilados». Mediterráneo Económico, $\mathrm{n}^{\circ}$ 5, 233-253.

RODRÍGUEZ SALMONES, N.; ARANDA, E.; GARRIDO, B. (2003): «El alojamiento turístico privado en el contexto del sistema de estadísticas de turismo», Estudios Turísticos, $\mathrm{n}^{\mathrm{o}} 155-156,7-32$.

Ros TundA, J. (2003): «Aproximación al turismo residencial español». Estudios Turísticos, $\mathrm{n}^{\circ}$ 155-156, 71-85.

SAlVÁ, P. (1979): «Las funciones residencial y de ocio como elementos de transformación del espacio rural de la Serra de Tramuntana de la isla de Mallorca». Trabajos de Geografía, no 35, 163-172.

SALVÁ, P. (1991): «El turisme com a element impulsor dels procés d'urbanizació a Balears (1960-1989)». Estudis Balearis, n 38, 63-70.

SAlVÁ, P.; SOCIAS, F. (1985): «Las residencias secundarias y la agricultura a tiempo parcial en las Baleares». El Campo, n 100, 64-67.

SAlVÁ, P.; BINIMELIS, J. (1993): «Las residencias secundarias en la isla de Mallorca: tipos y procesos de crecimiento». Mediterranée, $\mathrm{n}^{\circ} 1.2,73-76$.

SERrano Martínez, J. M. (2003): «Las viviendas de segunda residencia en la sociedad del bienestar. El caso de un país turístico: España». Cuadernos de Turis$m o, \mathrm{n}^{\circ} 12,53-75$.

SERrano Martínez, J. M. (2007): «El turismo residencial de la región de Murcia frente a los nuevos retos». Cuadernos de Turismo, $\mathrm{n}^{\circ} 19,189-216$.

Sola Alayeto, A. (1986): La residencia secundaria en Navarra. Tesis doctoral, Universidad de Navarra.

TORRES BERNIER, E. (2003): «El turismo residenciado y sus efectos en los destinos turísticos», Estudios Turísticos, n 155-156, 45-70.

VALDÉS, L.; TORRES, E. (2004): «El turismo de alojamiento privado. Propuesta metodológica para el análisis territorial de su impacto económico. Aplicación a Asturias» en Actas de la Primeras Jornadas de economía del turismo. AECIT. Castellón, 177-192

VALENZUEla RUBIO, M. (1976): «La residencia secundaria en la provincia de Madrid. Génesis y estructura espacial». Ciudad y Territorio, no 2-3, 135-152.

VALENZUEla Rubio, M. (1977): Urbanización y crisis rural en la sierra de Madrid. Madrid, Instituto de Estudios de Administración Local.

VALENZUEla Rubio, M. (coord.) (1997): Los turismos de interior: el retorno a la tradición viajera. Madrid, Ediciones de la Universidad Autónoma de Madrid.

VALENZUEla RuBIO, M. (2003): «La residencia secundaria en ámbitos metropolitanos: la Comunidad de Madrid». Estudios Turísticos, n $155-156,112-157$.

VALENZUEla Rubio, M. (2007): «Cambio turístico y nuevos horizontes residenciales». Ponencia en VIII Coloquio y Jornadas de Campo de Geografía Urbana. Acta. Ponencias y Comunicaciones. Palma de Mallorca. AGE-Grupo de Geografía Urbana, 261-302. 
VArela Merino, B; López Lago, A.; Martínez Serrano, A. (2003): «Primeras aproximaciones al estudio estadístico del alojamiento privado con fines turísticos desde una perspectiva de la oferta», Estudios Turísticos, nº 155-156, 87-109.

VERA REBOLLO, F. (2005): «El auge de la función residencial en destinos turísticos del litoral mediterráneo: entre el crecimiento y la renovación». Papers de Turis$m e, \mathrm{n}^{\mathrm{o}} 37-38,95-114$. 